\title{
Assessment of Lamellar Tearing
}

\author{
J. W. McEnerney
}

Prepared for the U.S. Nuclear Regulatory Commission Office of Nuclear Reguiatory Research Under Interagency Agreements ERDA 40-551-75 and ERDA 40-552-75 
Contract No. W-7405-eng-26

METALS AND CERAMICS DIVISION

ASSESSMENT OF LAMELLAR TEARING

J. H. McEnerney

Manuscript Completed - February 21, 1978

Date Published - March 1978

NOTICE: This document contains information of preliminary nature. It is subject to revision or correction and therefore does not represent a final report.

Prepared for the

U.S. Nuclear Regulatory Comission Office of Nuclear Regliatory Research

Under Interagency Agreements ERDA 40-551-75 and ERDA 40-552-75

Prepared by the OAK RIDGE NATIONAL IABORATORY

Oak Ridge, Tennessee 37830 operated by UNION CARBIDE CORPORATION

for the DEPARTMENT OF ENERGY

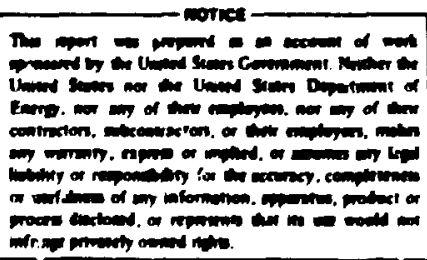


CONIENTS

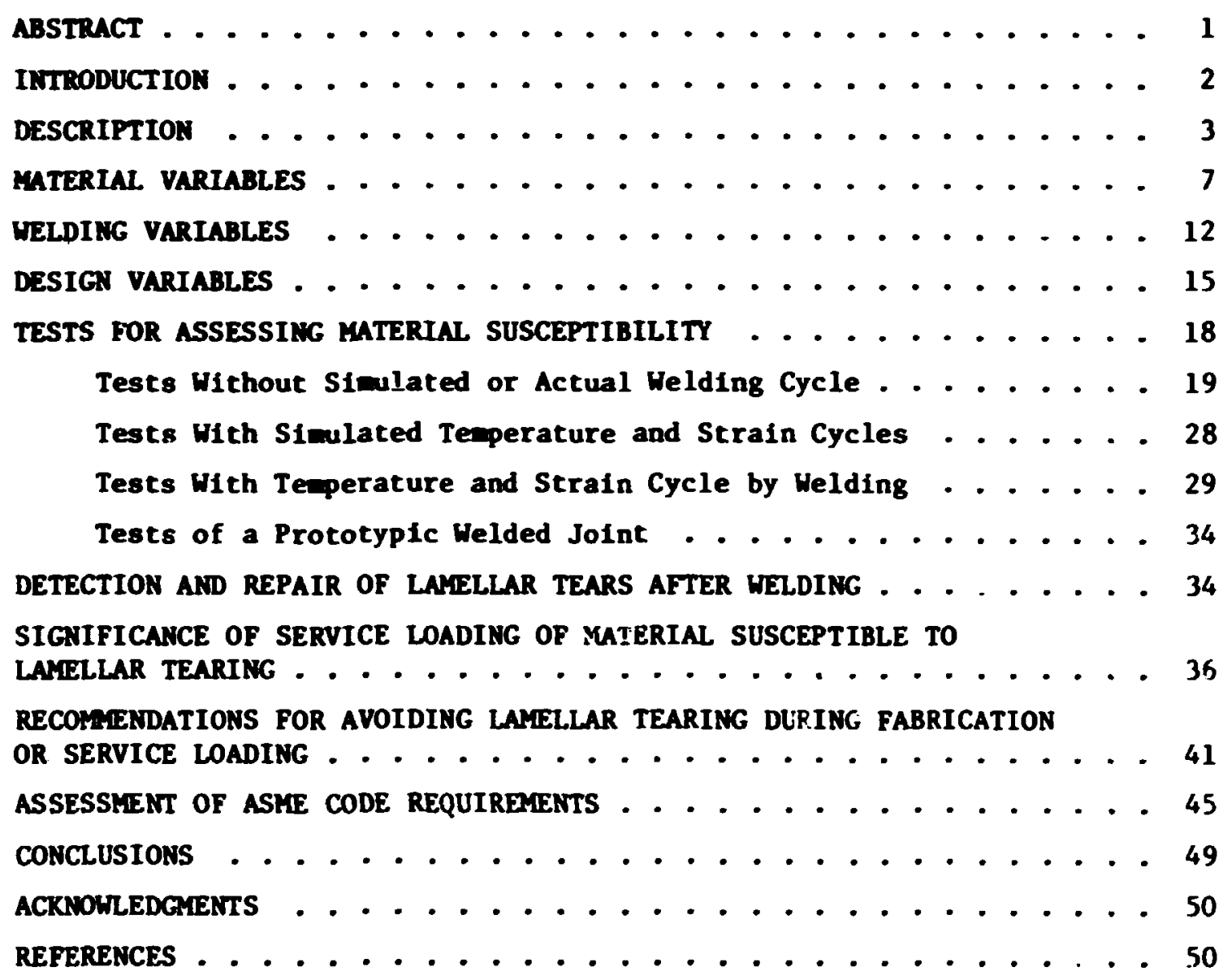




\section{ASSESSYEA I OF LAMEZLAR TEARING}

J. W. McEnerney

\section{ABSTRACT}

Information on lanellar tearing is sumarized and related to proposed ASME Code requirements.

Lamellar tearing is characterized as a conplex phenomenon related to poor short transverse ductility and throughthickness strain. Although nonnetallic inclusions play a coulnant role in lowering the ductility, steel matrix properties are also important. The through-thickness strain is generally caused by localized weld thermal contractions, but could result from certain service loads. The material, welding, and design variables that af fect lamellar tea:ing are shown to be conplex and interrelated.

The cotmonly reported tests for assessing material susceptibility are described, with the controversy over their validity being carefully detailed. Although the use of a nondestructive test such as ultrasonic examination is most desirable, a widely applicable test method does not appear to be available. Of the destruct've tests, the short transverse tensile reduction-of-area currently of fers the most applicable means of assessing material susceptibility. However, because of the importance of matrix toughness, the short transverse Charpy V-notch test should be considered for use as an addicional test if acceptance limits are developed.

The ultrasonic detection of lamellar tears is susceptible to interpretation errors, which can make it overly conservative and lead to unnecessary repairs. The repair of tears is described as costly, difficult, and sometimes ineffective.

Current ASRE Code Section III, Division 1. Subsection NF design requirements appear to preclude any failures during static and fatigue service loads. However, without improvement of short transverse ductility, certain dynamic service loads could cause lamellar tearing fallures. Two alternate design paths are recoumended to prevent tearing during fabrication or service loading. The more desirable path Improves short transverse ductility while the other relles on ultrasonic examination of finished welds or buttering. The current and proposed ASME Code section III, Division 1, Subsection NF requirements dealing with lamellar tearing are reviewed and recommendations are made. 


\section{INTRODUCTION}

Incidents of lanellar tearing have been reported in wost heavy fabrication Industries, such as shipbuilding, nuclear and fosstl power plant erection, bridge and building construction, production of of shore structures, and conventional pressure vessel fabrication. These incidents are pormally associated with the welding of hot-rolled carbon and low-alloy steel plates and shapes ande by ccnventfonal steelasking practices (CON). Table 1 lists some typical Anerican and British stee: specifications with reported ${ }^{1,2}$ histories of lanellar tearing. Because of the widespread occurrence, a considerable anount of research has been devoted to investigating the phenomenon. However, despite this research effort, there is st1ll disagreenent concerning various aspects of the lanellar tearing problen.

Table 1. Typical Anerican and British Steel Specffications yith Reporteda Histories of Lamellar Tearing

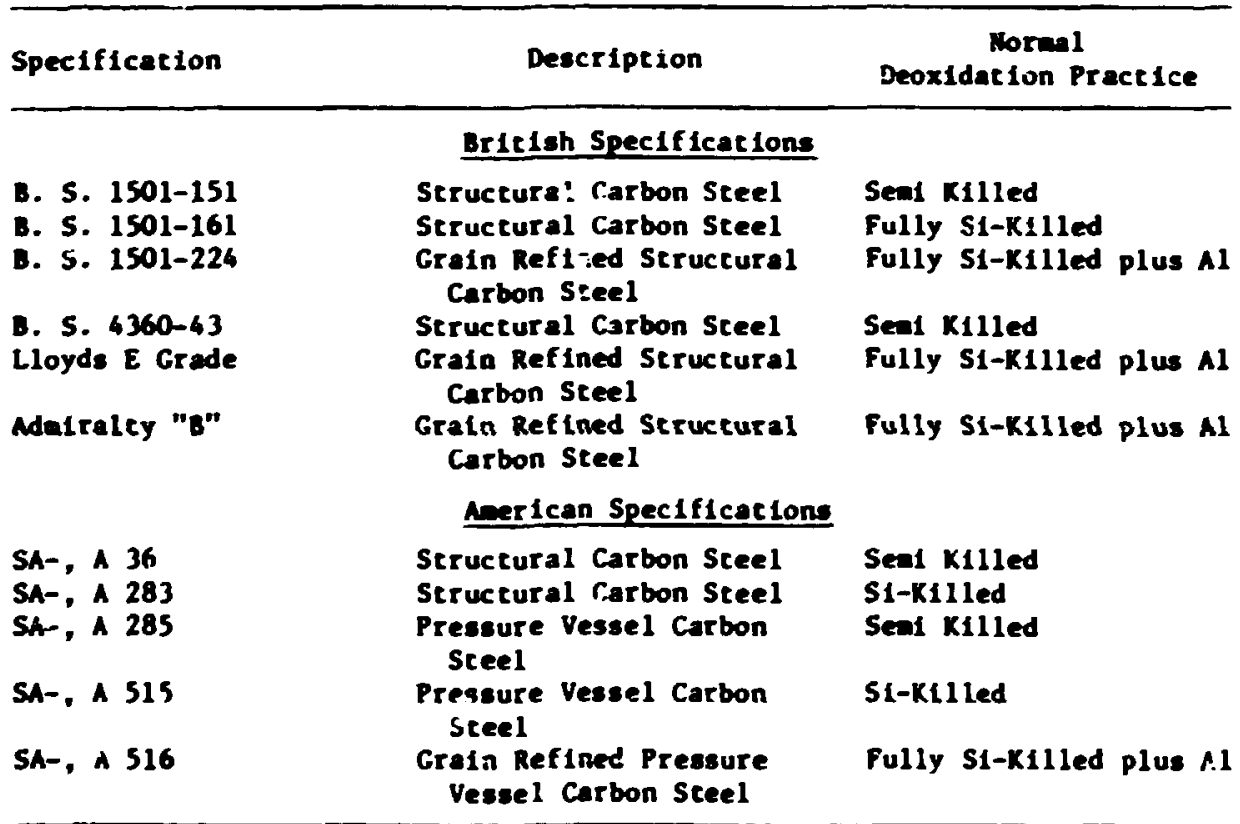

J.C.M. Farrar and R. E. Dolby, "Lamellar Tearing in Welded Stee:

Fabrication," Phase I of Investigations into Lamellar Tearing. A Compendiun of Reports from a Sponeured Research Programe, Welding Institute, Cambridge, Englend, March 1975; S. Ganesh and R. D. Stout, "Material Variables Affecting Lanel'ar Tearing Susceptibility in Steels," Weld. J. (Miami) SS(11):

341-9-354-s (Novemer 1976). 
An ASME Code conittee task group has been considering the problem of lamellar tearing for seve-al years. They are currently formulating requirements for ASTE Code Section III, Division 1, Subsection MF component support applications. The intent of this report is to sumarize the avallable information on lamellar tearing and then exanine its significance and the effectiveness of the proposed ASHE Code III-MF requirements.

\section{DESCRIPTION}

Lamellar tearing is characterized by a steplike cracking, which occurs parallel to the rollirg plane in susceptible steels that have experienced large strains in the through-thickness direction. Figure 1 shows a schematic representation" of lamellar tearing. The large strains usually result from the restraint of weld thermal contractions and therefore are ifighly localized. However, the strains could also result from loading a component in the through-thickness direction during service.

Lamellar tearing normally occurs in certain welded structures which are highly restrained. The restraint can be imposed by a massive component or by a smaller one which has been stiffened. Lamellar tearing is commonly reported ${ }^{1,3,4}$ to occur in the following types of structures: nozzle or penetration through a rigid plate, cylindrical stiffeners or closure plates, box structures, and stiffened structural joints such as beam-to-column. Figure 2 shows some examples ${ }^{1+7}$ of these structures. For highly susceptible material, tearing has been reported for low-restraint conditions, such as pullout of lif ${ }^{1}$ ing lugs and flange-to-web joints in the sabrication of I-beams.

The t:o basic joint designs that are subject to lamellar tearing are $T$ - (cruciform considered more severe form of $T$ ) and corner joints. ${ }^{1,3,4}$ Figure 3 shows examples ${ }^{1}$ of these joint designs. These joint types provide high restraint because weld thermal contraction is opposed by compressive forces in the base metal of the components being joined." Although the butt weld is not considered to be particularly susceptible, some instances of tearing have been reported.1,3 
OANL-DWG 77-19303

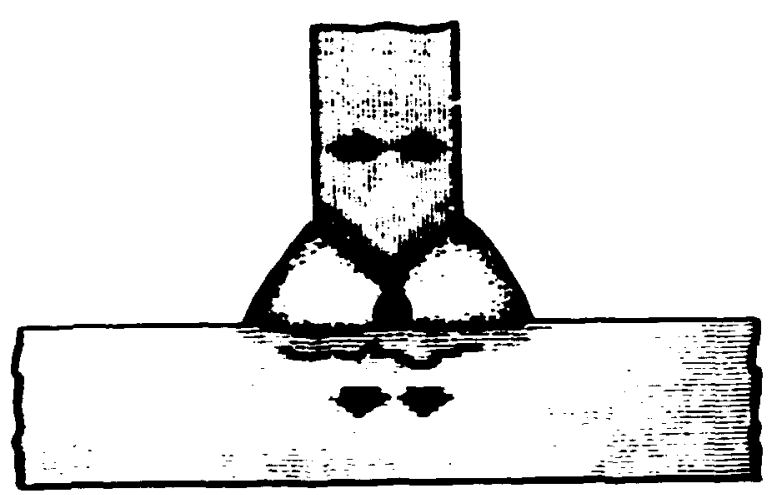

F18. 1. Schematic Representation of Lanellar Tearing Resulting Fron Weld Thermal Contraction in a Full Penetration T-Jolnt.

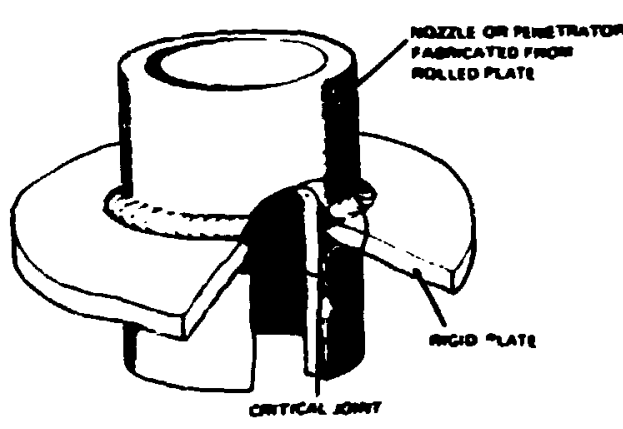

$\omega$

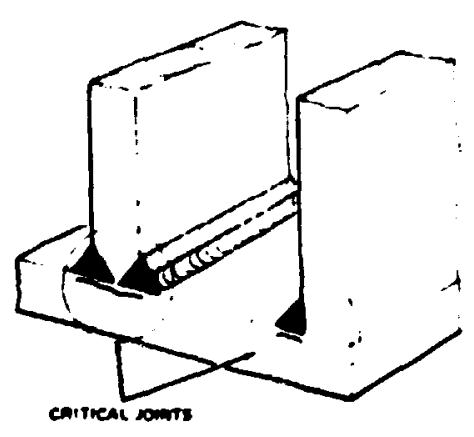

(a)

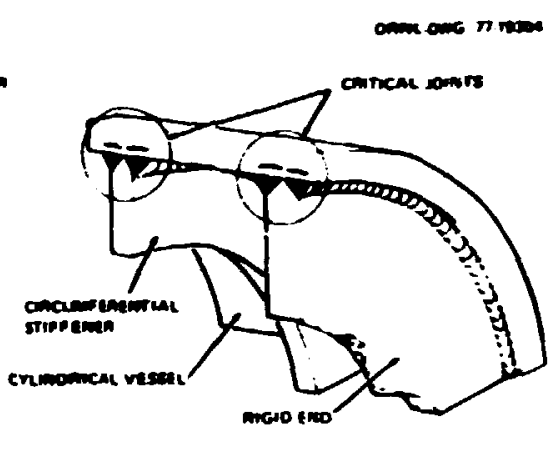

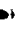

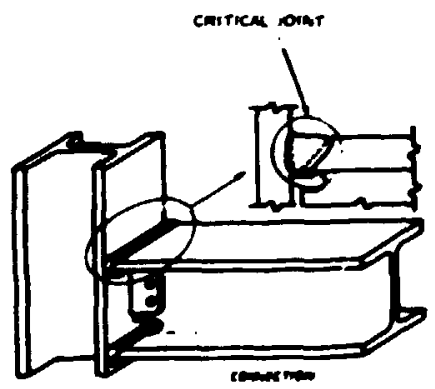

$\omega$

F18. 2. Structures in Which Lamellar Tearing Comonly Occurs. (a) Penetration through a rigid plate. (b) Cylindrical stiffener and endclosure plate. (c) Box structure.

(d) Bean to column. 


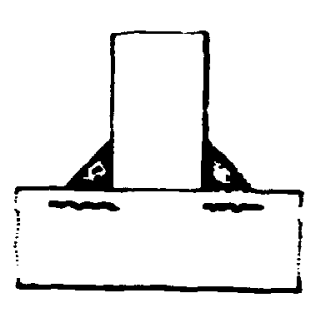

(a)

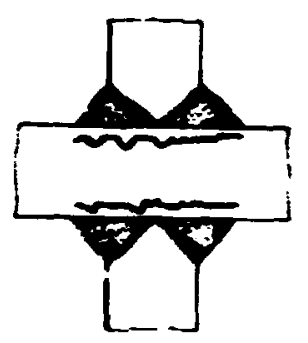

(c)
OAML Dung m.1930s

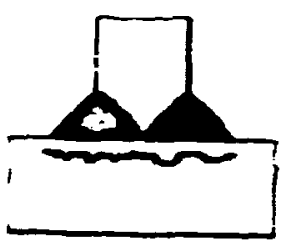

$\rightarrow$

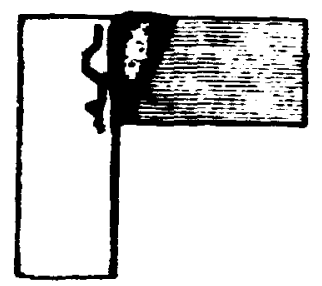

(a)

Fig. 3. [ypical Joint Designs that Suffer from Lamellar Tearing. (a) Fillet welded T-joint. (b) Fu.l penetration T-joint. (c) Fullpenetration cruciform $T$-joint. (d) Full penetration corner joint.

Lamellar tearing :1as been found ${ }^{1,2,4}$ from within the lower heat-affected zone (HAZ) (i.e., that region of the HAZ closest to the unaffected base metal) to well into the base metal thickness. The tearing may remain completely subsurface $o_{i}$ appear at plate edges or at weld toes. ${ }^{1}$

Considerable disagreement among investigators is reported ${ }^{2}$ concerning the time and temperature of the onset of tearing. In fabrication ${ }^{3}$ and testing ${ }^{2}$ situations, tearing has been reported to occur shortly after passage of the weld pool when previous beads have built up strain. The passing weld pool acts to cause: eransient overloading ${ }^{2}$ due to reduction in sectior. support, heating regions into the temperature range where ductility minimums ${ }^{3,3}$ can occur, and additional strain due to thermal contraction. However, others have $r \epsilon_{p}$ orted ${ }^{2}$ the tearing to be a room-temperature delayed cracking phenomenon. 
The steplike cracking that occurs has several distinct phases. Figure 4 schematically represents these phases based on a description by Farrar et al. ${ }^{\epsilon}$ Duriag the initiation phase volds are usually formed by decoherence or fracture of single elongated nometallic inclusiors or elongated clusters of the lying parallel to the rolling plane. Additional void initiation wechanisus are reported such as splitting along ferrite bands, ${ }^{2,7}$ liquation in reheated $\mathrm{HAZ},{ }^{2}$ intergranular cracking, ${ }^{2}$ hydrogen assisted cracking", and strain aging." However, most investigators ${ }^{2,1 \rightarrow}$ belleve that decoherence or cracking of inclusions is the primary initiation wechanism. The initiated void or tear, which is forned parallel to the rolling plane, is called a "terrace." 3 The second phase of lamellar tearing involves the linkage or growth of terraces on common planes. The mechanisms of terrace linkage that have been observed ${ }^{2}$ are necking, microvoid coalescence, "2ig-zag" tearing, intergranular cracking, quasi-cleavage, and cleavage. However, the most comonly observed mechanisms are necking and microvoid coalescence. ${ }^{2}$ The third phase of lamellar tearing involves the formation of vertical shear walls ${ }^{3}$ to connect

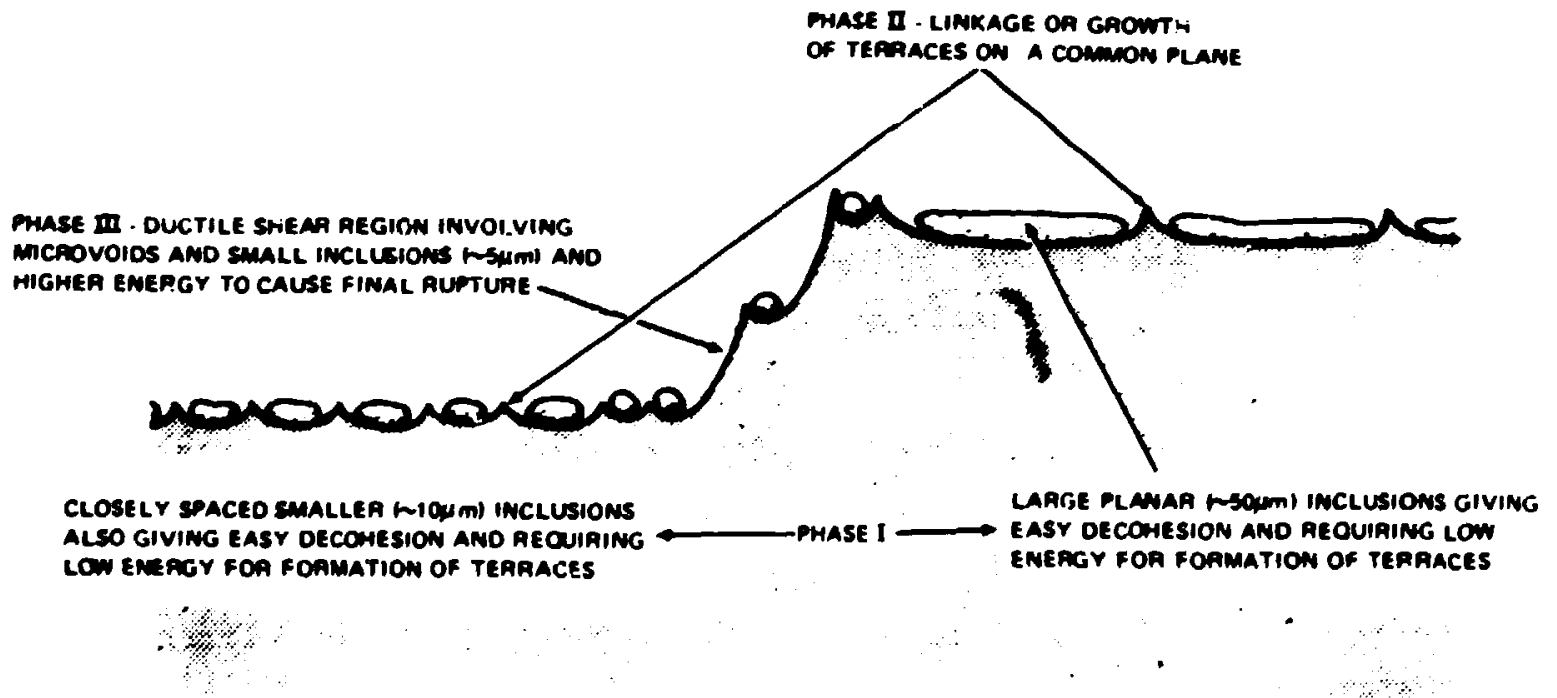

F1g. 4. Schematic Representation of the Phases of Lamellar Tearing. 
regions of Ilnked terraces on different planes. This third phase produces the steplike appearance of the cracking, and it occurs by ductile shear through regions of microvolds. ${ }^{2,5}$

Lamellar tearing itself has been reported, 5 from a fracture mechanics standpoint, as being a subcritfcal growth phase. Once the cra:k reaches a critical size through lamellar tearing, brittle fracture becones the postcritical growth mechanisw.

The foregoing description of lamellar tearing indicates that a number of complex interrelated variables control the phenomenon. Disregarding external load application, these variables can be generally grouped into three categories: material, welding, and design.

\section{MATERIAL VARIABLES}

The carbon and low-alloy steels that are susceptible to lamellar tearing have low short transverse (ST) ductility. This low ST is related $^{2}$ to three variables: nonmetallic inclusions, matrix properties, and embrittlement. Each of these variables can be associated with the previously described phases of lamellar tearing.

Most investigators agree that nonmetallic inclusions are primarily responsible for the low ST ductility. In conventional steelmaking practice (CON) the maximum sulfur requirement ${ }^{10}$ is above 0.025 wt $\%$. Depending upon charge or slagging the attained sulfur level can normally range from 0.010 to 0.030 wt $\%$. The dominant nonmetallic inclusions are sulfides and oxides. ${ }^{8}, 10$ The deoxidation practice determines what type of sulfides and oxides are present. ${ }^{\circ}, 10$ For correlation to lamellar tearing, Farrar and Dolby ${ }^{8}$ have classified the deoxidation practices into two categories: non-aliminum-treated and aluminum-treated. Table 2 summarizes the effects of deoxidation practice and inclusion types on lamellar tearing in coN steels.

Semikilled ( $<0.1$ wt $\% S i)$ and fully killed ( $>0.1$ wt \% St) are the normal deoxidation practices for the non-aluminum-treated steel grades of interest. In the semikilled and fully killed steels 
Table 2. Effects of Deoxidation Practices and Inclusion Types on Lamellar Tearing in CON Steels

\begin{tabular}{|c|c|c|}
\hline $\begin{array}{l}\text { Deoxidation } \\
\text { Practice }\end{array}$ & $\begin{array}{c}\text { Inclusion } \\
\text { Type }\end{array}$ & Effect on Lanellar Tearing \\
\hline \multicolumn{3}{|c|}{ Non-Aluninur-Treated } \\
\hline \multirow[t]{3}{*}{$\begin{array}{l}\text { Sent Rlled, } \\
\text { Fully Killed }\end{array}$} & Silicates & $\begin{array}{l}\text { Become wre elongated than the } \\
\text { sulfides during hot rolling and } \\
\text { are primarily responsible for } \\
\text { reduction in ST ductility }\end{array}$ \\
\hline & $\begin{array}{l}\text { Type I Manganese } \\
\text { Sulf Ides }\end{array}$ & $\begin{array}{l}\text { Dispersed globules are deformed } \\
\text { to lozenge-shaped inclusions } \\
\text { during hot rolling (aspect } \\
\text { ratio 2-20, length } 2-200 \mathrm{~m} \text { in } \\
\text { rolling direction) and general- } \\
\text { ly do not reduce ductility } \\
\text { unless there are locally high } \\
\text { concentrations }\end{array}$ \\
\hline & \multicolumn{2}{|c|}{ Aluninu-Trented } \\
\hline \multirow[t]{2}{*}{ Fully Killed } & $\begin{array}{l}\text { Type II Manganese } \\
\text { Sulf Ides }\end{array}$ & $\begin{array}{l}\text { Rod-shaped inclusions become } \\
\text { highly elongated during hot } \\
\text { rolling (aspect ratios up to } \\
\text { loo0, lengths several in } \\
\text { rolling direction) and are } \\
\text { primarily responsible for the } \\
\text { reduction in ST ductility }\end{array}$ \\
\hline & Alumina & $\begin{array}{l}\text { Although the Inclusions are } \\
\text { not individually elongated } \\
\text { during hot rolling, elongated } \\
\text { clusters or galaxies can } \\
\text { produce lccally poor ST } \\
\text { ductility }\end{array}$ \\
\hline \multirow[t]{2}{*}{$\begin{array}{l}\text { Fully Killed with } \\
\text { Excess Aluminum }\end{array}$} & $\begin{array}{l}\text { Type III Manganese } \\
\text { Sulf Ides }\end{array}$ & $\begin{array}{l}\text { Inclusions become highly } \\
\text { elongated during hot rolling } \\
\text { and are primarily responsible } \\
\text { for the reduction in ST } \\
\text { ductility }\end{array}$ \\
\hline & Alumina & Same as for fully killed \\
\hline
\end{tabular}


the oxides are present as silicates and the sulfide is present as type I anganese sulfide. ${ }^{2}$ The type I anganese sulfide normally precipitates in the ingot as dispersed globular inclusions. During hot working this sulfide is deformed to lozenge-shaped inclusions (aspect ratio 2-20, length 2-200 in in rolling direction). It is belfeved" that oxygen present in these type I Mins inclusions provides solid solution or dispersion strengthening, which prevents then from being readily deformed during hot rolling. Because of the lozenge shape and distribution, the type I manganese sulfide does not generally reduce the ST ductility unless there are locally high concentrations. 'Locally high concentrations can be caused by high sulfur levels $(\approx 0.5$ wt $z$ ) or segregation. The silicate inclusions are reported ${ }^{2}$ " to to principally responsible for reducing the ST ductility because they become more elongated than the sulfide inclusions during hot rolling. The more elongated silicate lecoheres in preference to lozenge-shaped sulfide because of greater stress intensification and lower surface energy. Because the silicates are primarily responsible for reducing the ST ductility, the sulfur level can give an incorrect indication of susceptibility to lamellar cearing in non-aluminum-treated steels.

Fully killed (>0.1 we \% Si, usually $0.02-0.08$ wt \% Al) and fully killed with excess aluminum (>0.1 wt $\mathrm{Z} \mathrm{Si,} \mathrm{>0.06} \mathrm{wt} \mathrm{\%} \mathrm{Al)}$ are the deoxidation practices for the aluminum-treated structural steel grades of interest. The oxide is present as alumina clusters or galaxies, and the manganese sulfide is present as type II for the fully killed and type III for the fully killed with excess aluminum. ${ }^{2,0,10}$ Depending upon the specific practice, variations of manganese aluminum silicates and aluminum silfcates can also be present. ${ }^{2}$ The type II manganese sulfite inclusions solidify in the ingot with a rod-shaped interdendritic morphology. ${ }^{2,8,10}$ Under certain rolling conditions at low temperatures, the type II sulfide can be deformed to give aspect ratios of up to 1000 and lengths of several millimeters. ${ }^{8}$ The type III sulfide inclusicrs solidify with an angular morphology. ${ }^{\theta}$ Because of the high plasticity of the type 111 sulfide inclusions during 
bot rolling, they can becone even more elongated than the type II. 2 The alunina galaxtes are trapped by steel dendrites during solidification. 10 Although alunina inclusions are not ladividually deforned during bot rolling, the groups or galaxies can be deforned inte elongated clusters depending upon their original spacing in the ingot. However, it is the sulfides that are reported ${ }^{2}$, as prinarily responsible for the low ST ductility in the aluninum-treated steels. An obvious question that can be raised at this point is whether or not non-aluninum-treated and aluninum-treated grades differ in susceptibility. In effect this question asks what is the difference between the silicates, which are doninant in non-aluninu-treated, and the sulfides, which are dominant in aluninum-treated. Oates and Stout $^{11}$ reported in 1973 that silicates were wore detrimental than sulfides. However, Ganesh and Stout ${ }^{2}$ In 1976 and surveys corducted by the Helding Institute ${ }^{l}$ reported that the phenomenon of lamellar tearing is too complex to simply relate susceptibility to steel grade or Inclusion type. Another study ${ }^{12}$ showed that the crack opening displacement to cause tear initiation was independent of inclusion type but depended instead upon projected lengths in the rolling plane. However, this study ${ }^{12}$ also showed that lower volume fractions of Type II manganese sulfide were required to achieve high projected lengths.

During sufficient straining in the ST direction, either the interface between the matrix and the elongated inclusions decoheres, or the inclusion fractures to initiate a tear. This tear initiation mechanism can be enhanced by differences in thermal expansion between the Inclusions and steel matrix. ${ }^{3}$ The sulfide inclusions, which contract wore than the steel matrix, ${ }^{2}$ can form a vold at the interface, thereby providing a site for the tear to initiate. The silicates and alumina, ${ }^{3}$ which contract less than the matrix, would form residual stresses, which could provide a source of stored energy to aid tear Initiation. It is therefore readily apparent that nonmetalific Inclusions play a primary role in the vold initiation phase of lamellar tear ing. 
The spaciug between the elongated inclusions is an iaportant factor in the linkage of ter:aces on comon planes. This spacing depends upen both the overall inclusion content and any mechanisms that tend to cause segregation. As the inclusion spacing decreases, less energy will be required to tear the intervening matrix. Therefore, the elongated inclusions also play an important role in the terrace linkage phase of lanellar tearing.

Small, finely dispersed inclusions such as alwina are fiportant in both the terrace linkage and shear wall formation phases. These inclusions provide sites for microvold formation. During tearing, microvold coalescence is enabled to readily proceed.

The properties of the steel matrix can be important in all phases of tearing. Ferrite-pearlite banding has been reported ${ }^{2}, 0$ as causing both initiation and propagation of lamellar tears. This is partially because the ferrite has a lower cleavage fracture stress than the pearlite. In addition, the lower toughness of the pearlite could provide a crack path. A previously described model characterizes lamellar tearing as the subcritical crack mode and brittle fracture as the postcritical mode. In terms of this model the fracture toughness of the matrix is very important with respect to cear propagation. The grain size of the matrix is an important factor 2 determining its fracture toughness. This is because the grain size affects the ductile-brittle transition temperature.

The thermal and strain cycles that result from welding can harden the steel matrix and thereby enhance both crack initiation and propagation capability. Crack initiation by splitting in a coarse-grained HAZ has previously been described.

strain aging has also been previously described ${ }^{3}$ as a mechanism that could putentially embritcle the HAZ and reduce Juctility. The introduction of hydrogen during welding provides yet another mechanism for assisting crack propagation. 


\section{MELDIMG VARIABLES}

The principal effects of welding on lanellar tearing are strain caused by restraint of theral contraction and a tesperature transient caused by heat flow from the passing wolten weld puddle. The variables that interact with these effects can be categorized as being related to the welding process or joint design. The joint design variables will be discussed in the next section.

Several welding varlables affect lamellar tearing susceptibility. These are reported $1,3,0,11,13$ to be heat input, preheat, filler material, and bead sequence. The effect of increasing heat input or preheat is reported ${ }^{13}$ to improve the postweld ductility. Ganesh and Stout $^{13}$ report four possible factors for the improvement in ductility due to high heat input:

1. Increased renetration, which causes interception and blunting of existing tears;

2. Increased deposition, which decreases the required number of weld beads and consequent strain cycles;

3. reduction in the cooling rate, which allows stress relaxation;

4. producing a softer and tougher HAZ.

An additional explanation ${ }^{1}$ is that higher heat input processes produce lower strength weldments, which will accommodate more of the strain. Although increased heat input has been reported to decrease the susceptibility to fallure, it increased ${ }^{13}$ the amount of subcritical tearing. These subcritical tears were located mainly in the coarsened HAZ. ${ }^{13}$ The localion and increased amount of subcritical tears might be detrimental diring some service loading conditions. In addition, the use of high heat input for highly restrained joints could lead to more overall shrinkage. ${ }^{3}$ In a survey ${ }^{1}$ of fabrication experiences, increasing heat input within a process was reported as inef fective.

The factors cited above for improvement in ductility due to high heat Input also apply to preheating. In addition Oates and Stout ${ }^{11}$ have reported that preheating can raise the temperature of certain materials above their brittle fracture transition, thereby retarding 
early propagation of lamel lar tearing. For material initially above its transition temperature, they reported a reduced effect from preheat and attributed the smail improvenent in tearing susceptibility to a reduction in thermal gradients. A survey of fabricators ${ }^{1}$ reported no successes with preheat, and one case of increased tearing. In general, when investigators discuss the effects of preheat, they usually ${ }^{5,13}$ add a warning that it may increase contraction strains. If elther the recomended material or inspection requirements described in a later section are used, restrictior: on the use of preheat are not felt to be necessary.

The proper selection of filler metal is important so that the strength of the base metal is not overmatched. If the weld metal is significantly stronger than the base wetal, none of the contraction strain will be accommodated by the weld metal. This results in an Increased strain buildup in the base metal with a subsequent increase In tearing susceptibility. Recomendations for limiting the strength of the weld metal are discussed later.

The sequence of weld bead deposition can significantly affect the amount of strain and how localized it is. The use of balanced bead deposition will keep the strain more symetrical thereby reducing localized buildup. The alternation of welding direction after each pass has also been reported ${ }^{13}$ to reduce initiation of lamellar tearing. The reason for this can be related to the initiation of tearing in multipass welds from a site where straining has been localized during earlier passes. Reversing the welding direction after each pass can reduce the localization of straining.

In addition to the welding variables described above, several techniques have been used to modify the thermo-mechanical effects of velding. These techniques are buttering, peening, and stressrelief heat treatment. In the buttering technique, the weld is made on top of a deposit of filler metal that has been previously applied to the plate and ultrasonically examined. The filler metal deposit consists of one or more layers, which are applied directly to the plate surface or in a gouged out area. Figure 5 (based on ref. .) 


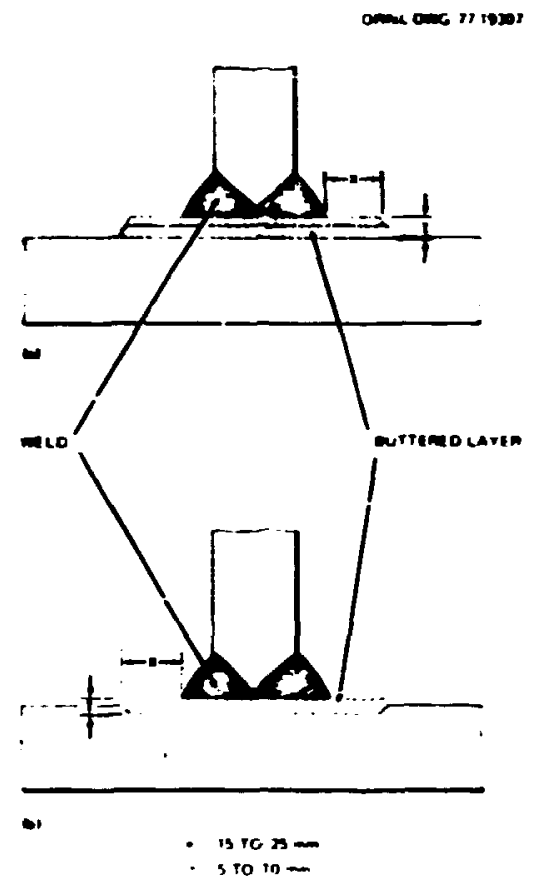

Fig. 5. Welds Made on a Buttered Layer (a) Applied Directly to Plate Surface and (b) Applied in a Gougen-0ut Area.

1llustrates welds made on a buttered layer. The recommended ${ }^{1}$ dimensions for the buttering layer(s) are that. it should extend 15 to $25 \mathrm{~mm}$ beyond each weld toe and be 5 to $10 \mathrm{mick}$. The purpose of the buttered layer(s) is to accomodate the weld contraction strains and displace the HAZ from the susceptible plate. As a result, the weld metal used for buttering should not overmatch the strength of the plate. Aiso, it is important to avold introducing hydrogen and to regulate heat input to produce sound buttering. ${ }^{14}$ Although the buttering technique has been reported ${ }^{1,14}$ to be very successful in avoiding lamellar tearing, a few instances of tearing resulting from bsttering directly on the plate surface [Fig. 5(a)] have been reported. ${ }^{l}$ In addition, one study ${ }^{15}$ reported that single buttering layers did not prevent lamellar tearing in a prototypic box section corner foint fabricated from susceptible plate. In general, if the proper controls are placed on the buttering procedure and an adequate size buttered layer is used, this techsique should be quite successful in preventing lamellar tearing. However, the cost for using this 
technique, the additional time required, and the chance of error introduced by any additional fabrication step nust be weighed against buying Improved steel.

Peening consists of mechantcally working the weld beads by hamer blows or shot impingercent to reduce residual stress, and thereby lessen the risk of lanellar tearing. Although peening has been used in the velding industry for a number of years in applications not reiated to lanellar tearing (prevention of distortion), the technique is not easily controlled and therefore is subject to a wide variation in results. In addition, it is reported ${ }^{16}$ to produce adverse effects such as reduction in toughness under certain conditions. A survey ${ }^{2}$ of fabricators indicated that peening reduced tearing in only one out of eleven reported cases. Although ASIE Code $^{17}$ Sect. III Division 1, Subsection NF currently allows the use of peening, it does not appear to be a visble method for reducing lameliar tearing. However, peening of weld metal should not worsen the rask of tearing in susceptible saterial and therefore need not be prohibited on the basis of lamellar tearing prevention.

Intermediate heat treatment is another technique that has been used to reduce residual stresses. For large components, which would require localized heating, this technique might increase the overall contraction strains. In addition, this heat treatment might cause some decoherence at inclusion-matrix interfaces and thereby increase the amount of indications seen by ultrasonic examination (UT).' In Reneral the technique has not been reported to be particularly successful.

\section{CESIGN VARIABLES}

The design variables that affect lamellar tearing are related to strain accimulation and concentration in the through-thickness direction. These variables can be divided inco two categnries: jojnt desigri and fabrication sequence. Three major factors in joint design affect the accumulation and concentration of 
through-thickness strain. These are weld orientation, balance, and siza. The orientation of the weld is obviously an iportant factor. If a weld is oriented such that it does not sause through-thickness contraction strains, then the likelihood of lanellar tearing should be elininated. Figure 6, based on refs. 1 and 4, 1llustrates methods for reorfenting the weld to reduce through-thickness contraction. In some $T$-joints, the weld can be reoriented by using a single electro-slag pass [Fig. 6(a)]. In corner joints the weld can be reoriented by placing the bevel on the plate that would have been through-thickness loaded [Fig. 6(b)]. Redesign of cosplex structural connections can often reorfent the weld to avoid through-thickness strain" [FIg. 6(c)].

The balance or symetry of a joint design is an important factor controling the concentration of strain. Joint designs that deposit the weld from one side cause the strains to concentrate and accumulate on that side. Figure 7 illustrates methods ${ }^{1}$ for balancing joint symetry to reduce the concentration and accumulation of strain.

The size of the weld is an important factor in joint design, which influences the amount of strain accumulation. In multipass welds the size of the weld determines how many passes are required to fill the joint. The number of passes subsequently influerces the amount of strain accumulation. Wide groove angles, unnecessary use of full penetration welds instead of simple fillets, and increasing the voluwe of weld metal to reduce the sectional loading stress are common occurrences that fncrease the size. Recomendation 3 for requirements to 1 imit the weld size are discussed in a later section.

The fabrication sequence is an important aspect of design, which can have a significant effect on strain concentration in a particular joint. The fabrication sequence determines the amount of restraint that eash joint in a multijoint component will experience. This restraint subsequently influences the amount of strain. If the more suscaptible joints in a component can be made initially or as separate subassemblies where restraint levels are lower, weld contraction strains will be allowed to disstpate. 

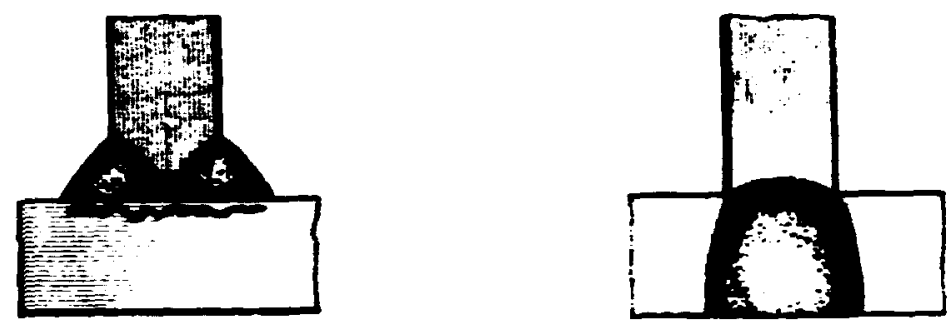

(b)
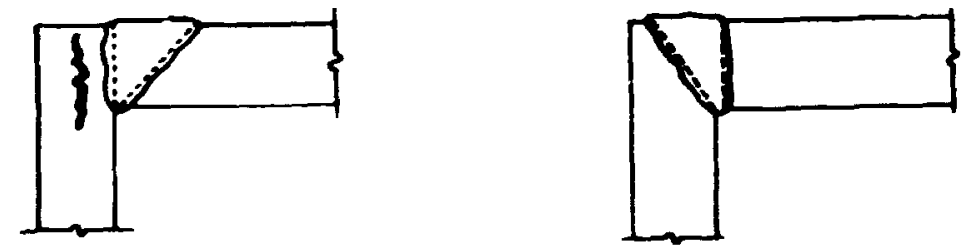

b)
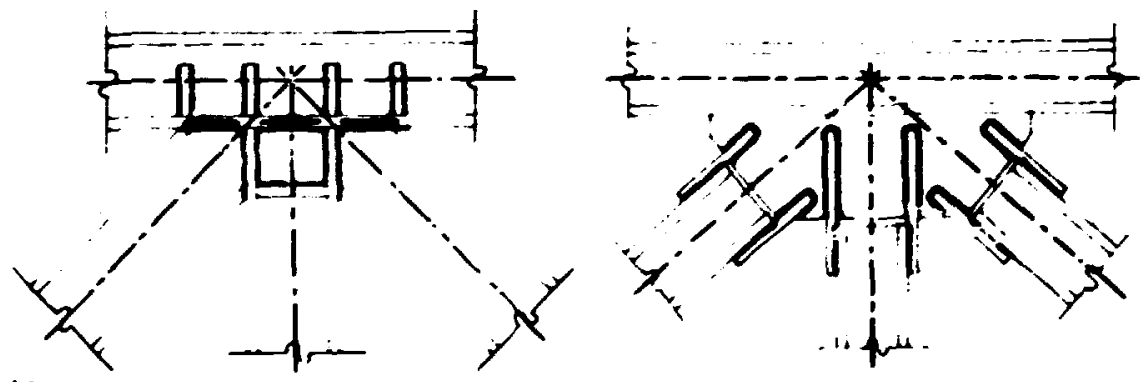

(c)

F18. 6. Methods for Reorlenting the Weld to Reduce Through-Thickness Contraction Strains. (a) Reorienting the weld in a T-joint by using a single pass electroslag weld. (b) Reorfenting the weld in a corner joint by placing a bevel on the susceptible plate. (c) Redesign of a complex structural connection to reorient the weld. 


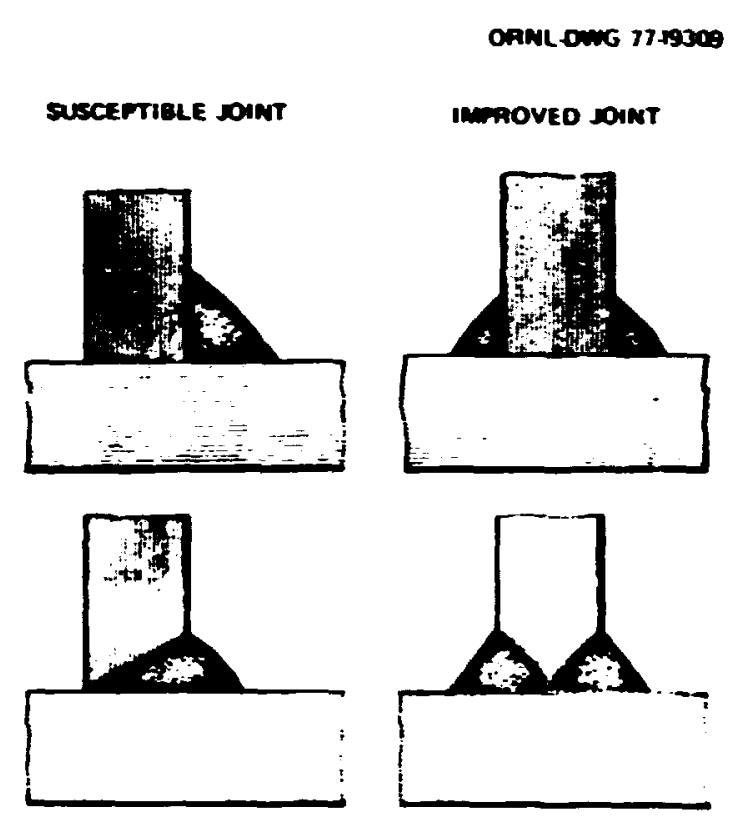

F18. 7. Balancing Joint Symetry to Reduce the Concentration and iccumulation of Strain.

\section{TESTS FOR ASSESSING MATERIAL SUSCE. IIBILITY}

The ideal $^{3}$ test for assessing susceptibility to lamellar tearing must be suitable for production quality control and incorporate the actual joint design, restraint, welding procedure, and material to be welded. However, in practice, while it might be possible to use the actual foint design and welding procedure, and to some degree the restraint, the material sample that is tested may not be representative of the actual area to be welded. This latter situation is due to the heterogeneous nature of ST ductility, which has been reported ${ }^{12}$ as varying between ingot yields of the same steel grade, between plates made from different locations within an ingot, and between different locations within the same plate. Unfortunatel; this situation can manifest itself in steels that have a low overall inclusion content yet have areas of localized segregation. Because of this situation, any destructive test inherently can incorrectly characterize the material whether the characterization be too optimistic or pessimistic. The use of a nondestructive examination (NDE) 
technique would then appear to offer the best solution since it would enable surveying an entire piate or just the specific areas to be welded.

Jubb $^{3}$ inas grouped the tests for assessing material susceptibility into the following four categories:

1. cests without simulated or actual welding cycle,

2. tests with simulated temerature and strain cycle,

3. tests with temperature and strain sycles by welding, and

4. tests of a prototypic welded joint.

The dowinant variable in these categories is the tesperature and strain cycle effects of welding. Although it is desirable to be able to test material without imposing the therwo-mechanical effects of welding, there is considerable controversy concerning the validity if it is not done.

\section{Tests Hithout Simulated or Actual Helding Cycle}

The tests without a simulated or actual welding cycle can be either destructive or nondestructive. Most of the reported work concerning the use of nondestructive tests has been performed at the Helding Institute. Because of the potential benefit of a nondesiructive technique, the Welding Insticute devoted a considerable amount of their work on lamellar tearing to developing an ultrasonic test. The result ${ }^{18}$ of their initial chree-year group-sponscred project was the development of a 5-MHz unfocused probe, which usad an integrated echo technique to examine discrete levels of thicknesses under both plate surfaces. The integrated echo technique ${ }^{10}$ measures the area under the reflections (a function of the size and number of reflections) and uses it to represent the volume fraction of inclusions. A short-pulse-length probe was used to correct for interface echo masking of the layer under the surface being scanned. A normal-pulse-length probe was used for the surface layer opposite the side being scanned, with correction for signal attenuation from intermediate inclusion layers. Corrections were also made for variations in surface finish. Because of the differences 
in predoninant inclusion types, separate calibration curves were developed to relate integrated echo aplitude to short transverse percentage reduction of area (ST $Z$ RA) for aluninu-treated and non-alunimu-treated steels. Wide-scale evaluation ${ }^{39}$ of the technique discovered that incorrectly high values of ST $Z$ RA vere being predicted because of variations in Inclusion population and Inclusion-steel natrix interface (resulting from different cheral and wechanical treatments) for different grades of steel. From these results it was concluded ${ }^{19}$ that the developaent of a technique applicable to a wide range of steel types was not probable. Additional work at the Welding Institute ${ }^{19}$ on the UT technique has been ained at simplification of the procedure to elininate the need for complex calibrations. The need for surface finish corrections vas eliminated by using one standard finish. Corrections for attenuation of reflections from the back wall were eliminated by only scanning the surface layer from one side. Instead of attempting to predict ST $Z$ RA, direct comparison is made with standards. Although sone success has been reported ${ }^{19}$ with this simplified technique, it is presently limited to a narrow rarge of steel types, or to predicting relative variations in a given plate.

However, a fabricator in Italy ${ }^{20}$ recently correlated ST $Z$ RA and ultrasonic test results. In addition, specifications for specific steels to be used in North Sea of fshore structures are using both ultrasonic inspection and ST Z RA as susceptibility tests. ${ }^{21}$ Even with these reported successes, it still must be realized that the application of ultrasonic examination to the determination of ST $\%$ RA in a wide range of materials will be difficult.

Several destructive tests are performed without a simulated or actual welding cycle. While some of these tests require actachment welds for grjpping or support, the we?ds are not meant to provide temperature and strain cycles. The more commonly reported tests are tensile, slice bend, Charpy v-notch (CVN), and analysis of inclusion population. 
The ST tensile test is currently the cost controversial test for assessing susceptibllity. The controversy is because the test offers a standardized method readily applicable to quality control which makes it highly desirable, yet its variability and correlation with lawellar tearing are disputed. The use of the ST tensile test is reported ${ }^{12,21}$ as already being an integral part of stecl specifications for critical applications such as offshore structures. In addition, it is reported ${ }^{21,22}$ that this test has been included in recently issued experimental standards In France and Gernany. The ST tensile property that is most frequently used is $Z \mathrm{RA}$. The $Z \mathrm{RA}$ is considered ${ }^{23}$ to provide a good indicacion of ST ductility associated with a fracture propagating parallel to the rolling plane. It is also reported ${ }^{11}$ to be the tensile property that correlates nost closely with tearing susceptibility. In addition, it can be more easily standardized than elongation since gage length will vary with plate thickness. The validity of the ST tensile test is usually questioned because of the following: ${ }^{3,24}$

1. only a small cross-sectional area of material is tested, resulting in a statistically small sampling;

2. the fracture of the test specimen usually occurs near the center of the plate, while the surface region is where lamellar tearing is reported;

3. the results can be greatly influenced by single large inclusions or clusters, while neglecting the steel matrix properties;

4. there are conflicting reports as to the correlation between ST $z$ RA and susceptibility to lamellar tearing.

The concern about the statistically small area sampled is related to the reported ${ }^{12}$ heterogeneous nature of ST ductility. Any of the destructive tests that rely on a sampling plan are subject to this error. Although some cests may evaluate a larger area, the total area tested will always be a small fraction of the materdal it represents. One philosophy that can be used to justify this test is that if a sufficiently high minimum ST ductility acceptance 1 imit 
is usei, then the poor areas that my escape testing should be sall and localized and therefore not create significant tearing. This philosophy is supported by the detalled investigation ${ }^{12}$ of ST $Z$ RA of the plate ylelds of two froduction ingots of fully siliconkilled carbon-manganese steel. Figure 8 shows the location and dimensions of the plates ${ }^{12}$ produced from the two production ingots. The testing consisted of 23 sets of tests fron ingot $A$ plates and 21 from ingot $B$ plates with six leralized specinens per set. Figure 9 shows the reported ${ }^{12}$ cest locations and the ST $Z$ RA values. The ST $Z$ RA values of the ingot $A$ plates were higher and wre consistent while those for the ingot B plates varied considerably. If the conservative recomended ${ }^{2}, 16$ miniman ST $Z$ RA acceptance linit of $25 \%$ is used, then none of the sets from ingot B would be acceptable, while seven sets from ingot $A$ would have been rejected. This indicates that the use of a conservative minimen acceptance linit can screen out plates with 10 and widely varying ductilities. It also shows that the linits can be overly conservative.

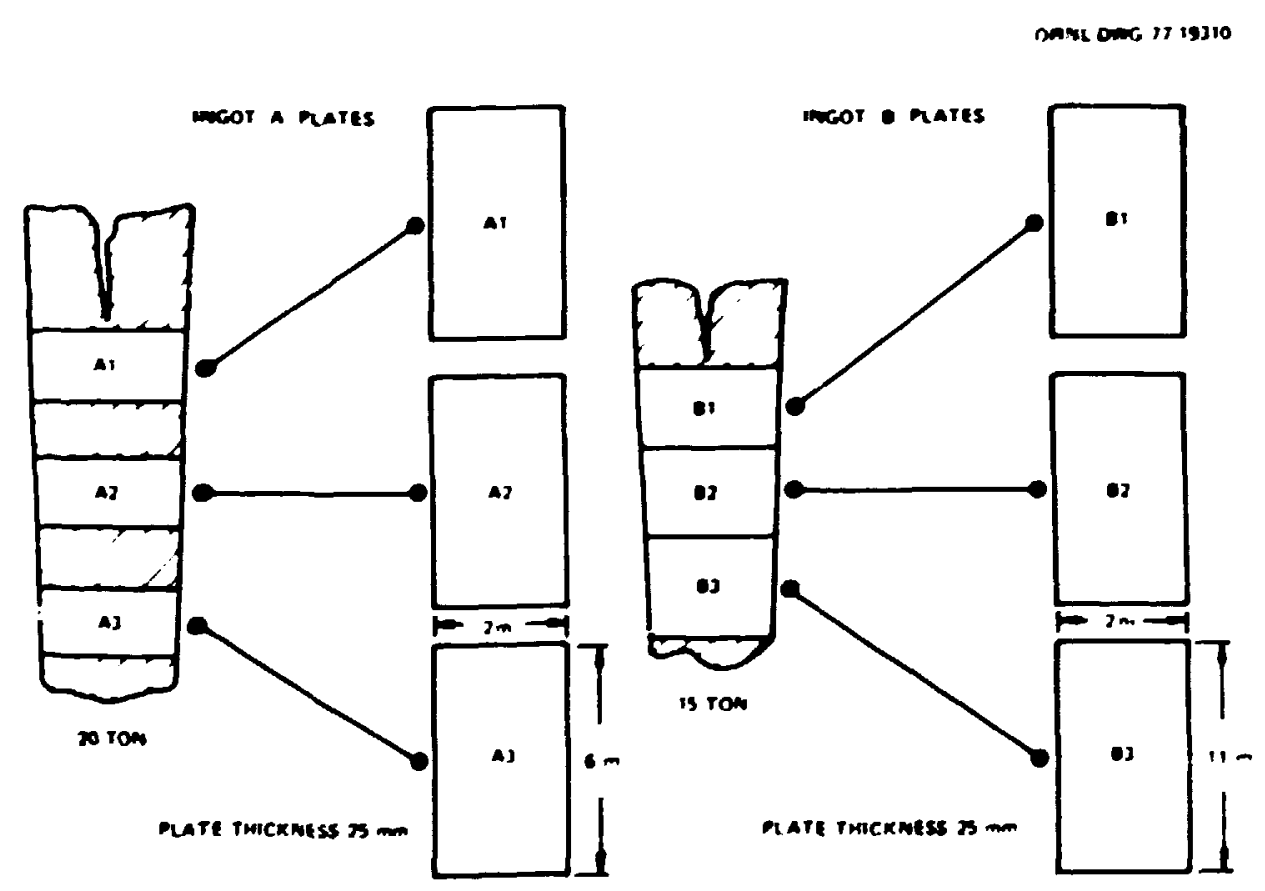

F1g. 8. Location and Dimensions of the Plates Produced from Two Production Ingots. 

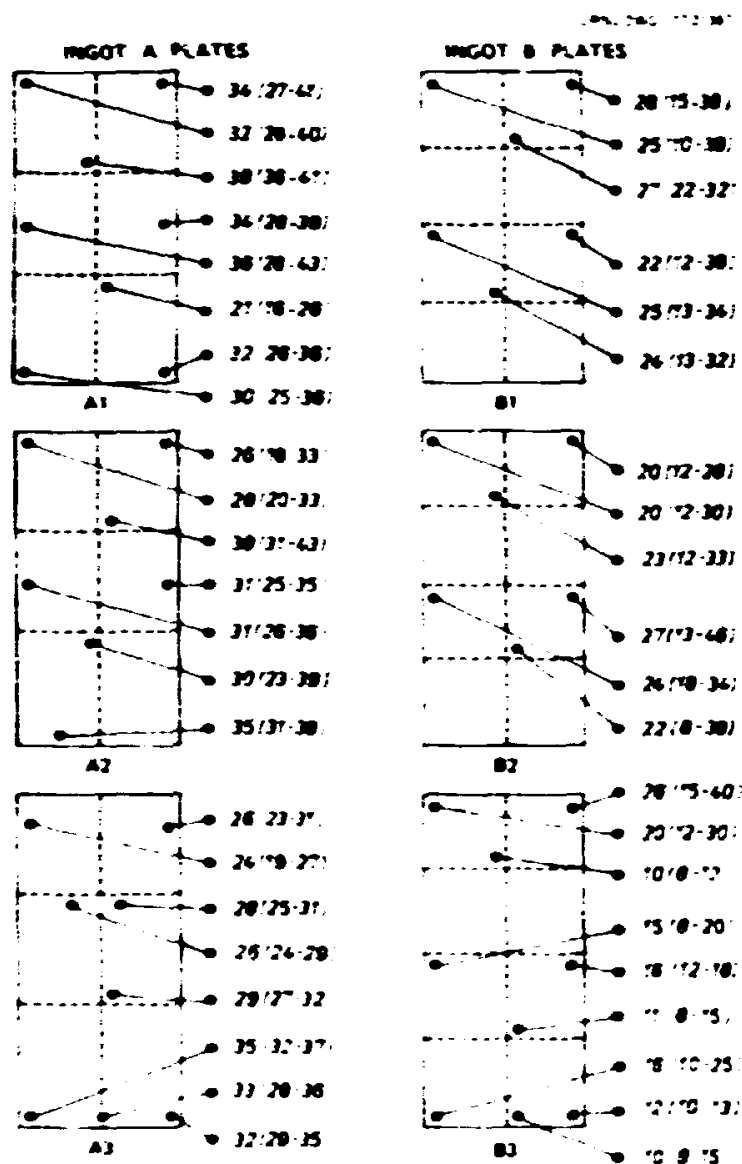

Fig. 9. Location of Tensile Tests and ST Z ZA Values, Mean (Range), for the Plates Produced from the Two Production Ingots.

The location of the ST tensile test has been a concern because it does not test the surface area, where tearing normally occurs. Oates and stout reported" significant differences in ST : RA (average of 19.4 vs 2.87 ) between specimens with gage lengths centered on plate mid-thicknesses vs $6.4 \mathrm{~mm}$ from the surface of 64-m plate. This could be because surface regions are reduced more during hot rolling and the inclusions located there could be more elongated. However, the restraint of plastic deformation by the hardened HAZ of the wẹld attaching the testing grips must also be considered. One investigation' has already shown that when the plate thickness is below $30 \mathrm{~mm}$, ST $\% \mathrm{RA}$ begins to decrease from restraint of plastic deformation by the phz of the grip attachment welds. The uze of friction welding for grip attachment produces a small HAZ and is 
the recomended procedure.' In addition, heat treatment of the attachwent welds has been reported ds a mean:; of ellninating the restraint from the Haz.' However, this technique would also heattreat the base wetal and alter its properties. Lanellar tearing occurs near the plate surface because of localized therwo-mechanical effects of the weld cycle. More data need to be developed to indicate whether the surface material is wore susceptible.

Large single Inclusions or clusters have been reported ${ }^{12}$ to reduce the ST $Z \mathrm{RA}$. These decreased ST $Z \mathrm{RA}$ values do not necessarily account for the resistance to further tearing that the steel matrix nay have provided. The effect of the large inclusions or clusters can therefore be vieved as making the test more conservative.

Several studies $5,9,23,25$ have shown a correlation between ST $Z$ RA and sisceptibility to tearing and have mace recomendations for acceptance 11mits. However, another Investigation ${ }^{11}$ has reported an apparent lack of correlation. In one study, 2315 steels with known fabrication history of tearing and 20 with known fabrication success were evaluated to determine any correlation between ST 7 RA, -tearing histo:y as a result of fabrication, and type of structure (1.e., degree of restraint). The results of this study were three acceptance limits for ST $\Varangle$ RA based upon folnt restraint. These minimum ST $Z$ RA acceptance 11 mits are $25 \%$ for high restraint such as nozzle penetrations, $15 \%$ for moderate restraint such as box and cructform joints, and $10 \pi$ for 11 ght restraint such as fabrication of I-beams. In addition, the following points were made:

1. the acceptance limits are appropriate to ylelds strengths below $400 \mathrm{MPa}$ ( $58 \mathrm{ks} 1$ );

2. specimen extraction should be from the most critical fabrication region or from a number of locations;

3. at least $s i x$ specimens should be tested from any area being evaluated;

4. the test is prone to large scatter. Areas having a wide range of ST $\%$ RA values Indicate low risk of tearing. Only consigtently low values, with a low mean and narrow range, indicate a high risk of tearing. 
Another study' correlated tearing susceptibility of 40 steels with ST $Z \mathrm{RA}$, as ranked by five residual stress levels in the Welding Institute Window Test. ${ }^{26}$ The study showed a good correlation between susceptibility and ST Z RA, with the sase scatter trends as previously reported ${ }^{23}$ ( $1 . e .$, scatter increasing as susceptibility decreases). As a result of this study the following minimum ST $z$ RA acceptance 1 inits were recomended: $25 \%$ for high restraint, 157 for moderate restraint, and 87 for low restraint. One investigation ${ }^{15}$ consisted of correlating tearing in three steels (with varying ST $Z$ RA and fabrication histuries) during fabrication of five types of test structures with various levels of restrajint. The result of this stuciy again was a set of minimum ST $Z$ RA acceptance $1 \mathrm{fmits,}$ which were: $20 z$ for highly restrained, $15 \%$ for moderately restrained, and $10 z$ for lightly restrained. It was also noted that the possible error for measurement for ST $Z \mathrm{RA}$ was high in the range 0-20\%. In a final study, 5 the incidence of tearing in three large weldment assemblies (representative of pressure vessel fabrlcations) was compared with the ST 7 RA of the ASTM A 515 grade 65 steel plates used. The result of the investigation was a guideline of $16 \%$ minimum ST 7 RA for the specific fabrications and material type used. However, in one investigation, 'i which compared ST \% RA with the critical amount of weld restraint needed to cause tearing during the Lehigh Lamellar Tearing Test, no apparent correlation was found. The slice bend test ${ }^{24,25}$ is another destructive test that is performed without the thermo-mechanical effects of the weld cycle. The test was developed to provide a means of assessing tearing susceptibility suitable for plant quality control without some of the disadvantages of the ST tensile test. Although the slice bend test offers some improvements in tw'-ing technique, it is still susceptible to the sampling problems associaced with all destructive tests. The original test. procedure 25 has been modified. It is currently" performed by attaching a thin slice of plate to a backing bar and then subjecting the composite to three-point bending such that the through-thickness direction of the slice is in tension. Figure 10 shows the manufacturing and testing sequence ${ }^{24}$ 

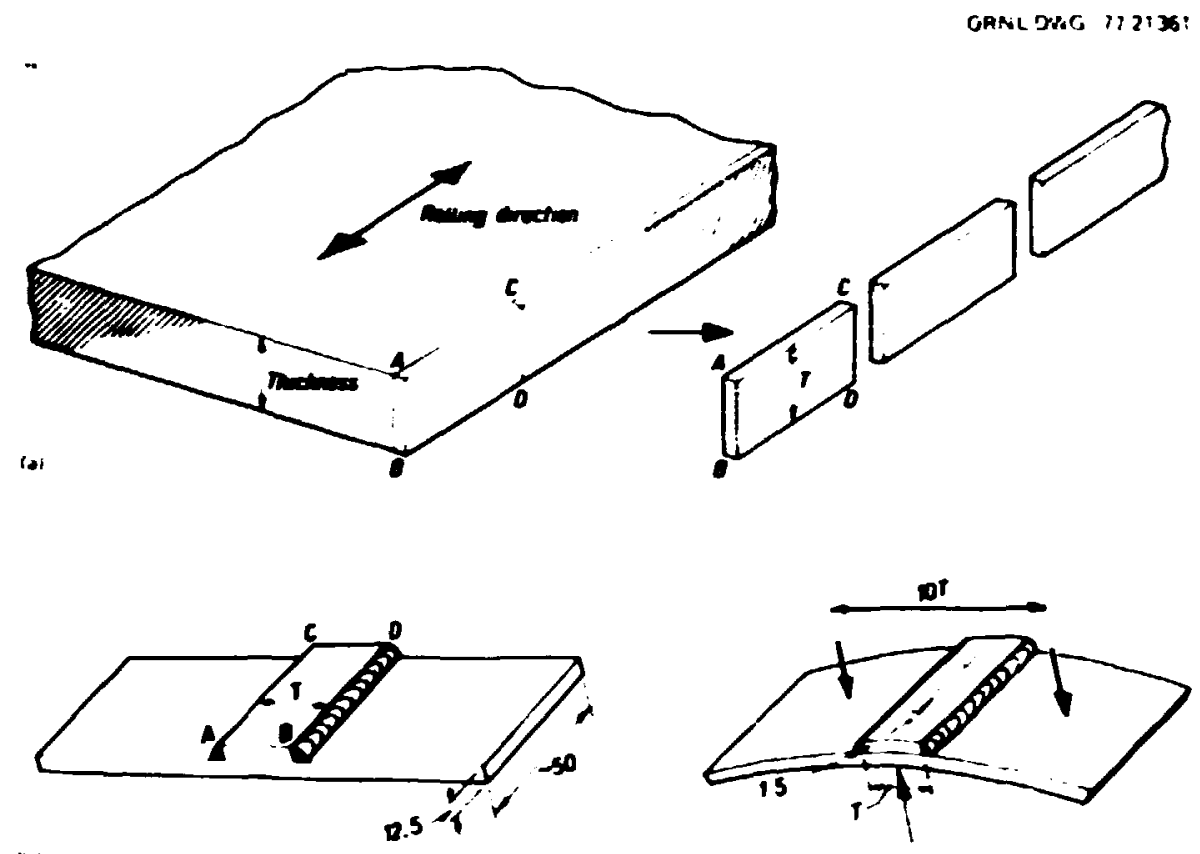

(b)

Fig. 10. Manufacturing and Testing Sequence for the Slice Bend Test. (a) Rewoval of slice from plate. (b) Attachment of slice to backing bar. (c) Three-point bending of the composite to produce through-thickness strain in the slice.

for the slice bend test. The heavy backing bar enables uniform straining across the thickness, and the amount of strain imposed is controlled by varfous measuring techniques, which were st111 being investigated. The criterion for assessing tearing susceptibility is the measurement of total tear length that has progressed through the linkage or shear wall stages for a given testing strain. By relating the testing strain to joint restraint levels, a maximum tear length acceptance limit can be established for various testing strilns. Although the slice bend test requires more work on strain measurement technique and establishment of tear length acceptance criteria, the following advantages ${ }^{24}$ indicate that it should be given further consideration:

1. It is a simple test, which can be readily performed on a plant quality control level;

2. the test evaluates the complete thickness; 
3. the test froduces realistic lamellar tearing and assesses the imortant linkage and shear wall stages, thereby enabling it to be wo sensitive and possibly reduce the overconservatism of the ST tensile test.

The ST Charpy V-notch (CWN) test is another destructive test that is usually performed without the thermo-mechanical effects of a weld cycle. However, attachments must be welded for testing thin plate or locating the notch near the surface. This test is highly standardized and readily usable for plant quality control. There has been some controversy ${ }^{3}$ concerning the ap.licability of the CVN test, since it has a higher strain rate than that associated with lamellar tearing. In addition, because the test only evaluates the plane parallel to the notch, it does not necessarily test the most susceptible region. Two studies report ${ }^{5,11}$ a correlation between tearing susceptibility and CVN tests. One study correlated CWN tests with prototype weldments ${ }^{5}$ while the other utilized the Lehigh Lamellar Tearing Test. " ${ }^{1}$ The result of the prototypic weldment study was the proposal of an acceptance limit for the specific joint types and material that were evaluated. However, another study, which evaluated susceptibility by the Welding Institute Window Test, concluded that there was no definite correlation. The CVN test appears to be more applicable to characterizing the linkage or shear wall stages of tearing or the brittle fracture mode when the lamellar tear has reached a critical size. Silice chis test will be sensitive to changes in matrix properties, it would appear to be a good test to run in confunction with ST tensile cests, as already suggested. 5 The main problem is that there are no widely applicable acceptance limits avallable.

The analysis of inclusion population by quantitative metallographic examination is another testing method that is performed without imposing the effects of a welding cycle. The parameters that have been used to characterize the inclusion population are: number, volume: fraction, length (parallel to rolling plane), aspect ratio, mean free path, and projected length. Because of the small area scanned per sample, this 
nethod would probably require an extensive sapling plan. The high costs of autometc scanning equiprent and large number of tests required do not ake this testing wethod readily applicable as a plant quality control tool. In addition, there is some controveray concerning the correlation between inclusion population analysis and susceptibility to tearing. Generally, the correlation between susceptibility and nuber or volune fraction of inclusions has been reported ${ }^{3,12}$ to be weak. Correlaition 18 improved by using factors related to inclusion length, as evidenced by the reported ${ }^{12}$ correlation between ST $z$ RA and maximin lisclusion length. The inclusion projected length, which 18 the total lengch of inclusions parallel to the rolling plane per unit area, is reported ${ }^{12}$ to relate several inclusion population variables to the direction of fracture propagation. The projected length has shown ${ }^{12}$ good correlation with notched bend test maximum crack opening displacement (COD). However, in another investigation, 2 the inclusion analysis did not provide a good correlation. The possible explanation reported for this poor correlation was that the quantitative analysis did not account for smaller inciusions or matrix properties that affect the propagation of tears.

Tests With Simulated Temperature and Strain Cycles

Simulated weld temperature and strain cycles can be imposed on specimens that have been sectioned from the material to be evaluated. Equipment such as the Gleeble is currently available and capable of providing a simulated HAZ with the proper orientation to the throughthickness direction. However, this type of testing is more suitable for latoratory investigations than for production quality control. One investigation' has reported using this weld cycle simulation technique and then performing tensile tests. The results of this testing showed a decrease in the ratio of ST to longitudinal direction RA. 
Tests With Tewperature And Strain Cycle By Welding

Two categories of tests within this group use welds. Methods such as the Cranfield Test, Welding Institute Window Test, and Lehigh Lamellar Tear Test use a weld to make a direct assessment of the tearing that results. In concrast, the ST notched bend test utflizes the resultant $\mathrm{HAZ}$ from a veld to enable COD testing In the region where tearing normally occurs. In testin, methods in this group are still susceptible to the sase sampling errors af fecting all destructive tests.

Although the ST notched bend test can provide COD neasurements of unaffected base metal, the reported studies ${ }^{12,27}$ have examined the HAZ of welds. In these ST notched bend tests ${ }^{12,27}$ full plate thickness specimens are removed and attachments are welded to the two surfaces parallel to the rolling plane. Figure 11, based on ref. 27, shows the manufactiring and testing sequence for the specimens. One weld is a square butt rade by electron beam

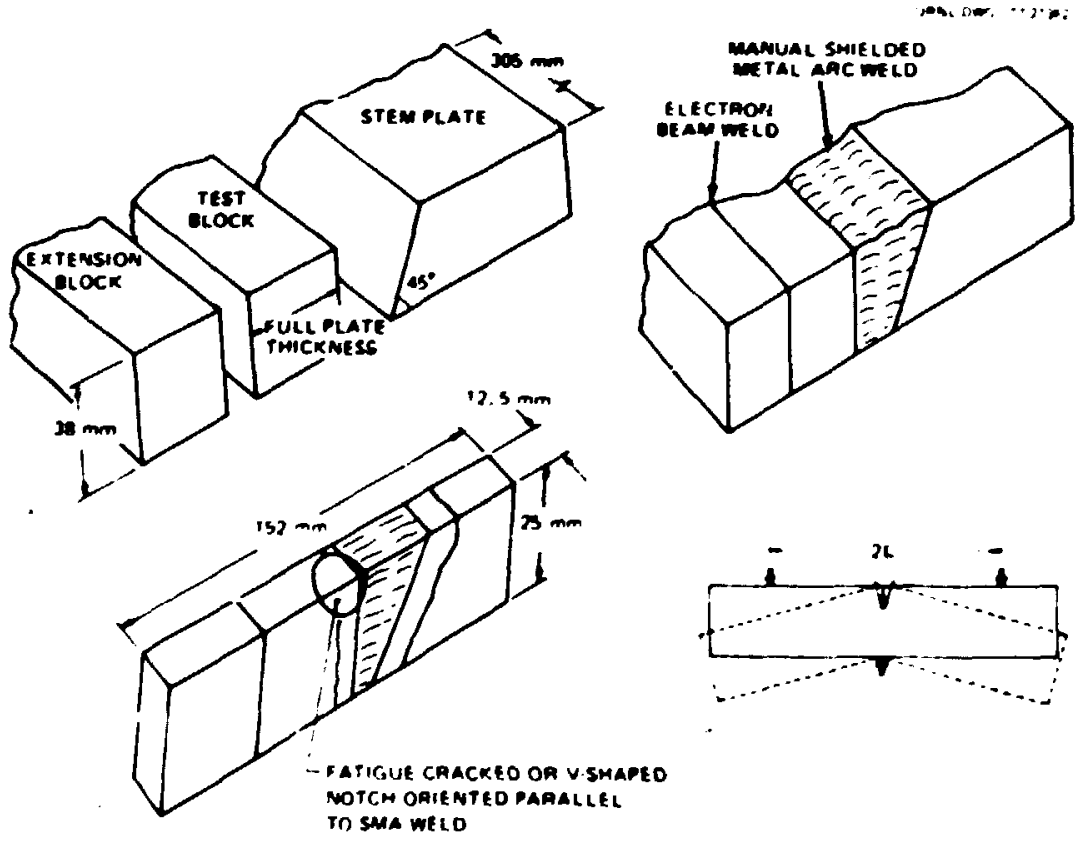

Fig. 11. Manufacturing and Testing Sequence for ST Notched Bend Specimens. (a) Assembly of components for composite specimen. (b) Welding attachments. (c) Machined specimen. (d) Testing of specjmen. 
and is eant only to attach an extension block [Fig. 11(b)]. The other weld is a $45^{\circ}$ bevel-groove made by the manul shielded metal-arc (Sin) process to attach the stem plate [Fig. 11(b)]. The multipass SHA weld is used to impose through-thickness strains and thernal cycles. After the welds are made, specinens are machined from the composte, and a fatigue cracked or $V$-shaped notch is oriented parallel to the Sth weld, at various locations in the vicinity of the HAZ [Fig. 11(c)]. During three-point bending, COD measurements are ade as crack inftiation and propagation occur on a plane parallel to the plate surface [Fig- 11(d)]. The COD to maximu load ( $\delta \max$ ) is normally used as the assessment parameter because other values, such as the area under the load vs displacement curve, are too dependent upon test machine stiffness. ${ }^{27}$ In one investigation, 12 quantitative metallographic analysis of inclusions was performed on samples adjacent to the notch bend test specimens. As previously reported, a correlation was demonstrated between the mean $\delta$ max and the inclusion projected length. This correlation was shown to be independent of the type of inclusion. However, attempts ${ }^{27}$ to correlate notched bend test results with fabrication history or ST 7 RA have shown discrepancies because the notch location did not coincide with the most susceptible area. The notch bend test has been characterized ${ }^{27}$ as unsuitable for production quality control because it is a complex and expensive test to run.

The Cranfield Test $^{20}$ consists of a stem plate and a section of base wetal to be tested. Figure 12 shows the details of the Cranfield Test specimen, adapted from ref. 28. The end of the stem plate $1 \mathrm{~s}$ beveled such that it forms a 45 or $60^{\circ}$ Vee when seated on the surface of the base metal plate. Multipass welding of the VEE, with interpass cooling to allow full thermal contraction, results in a large strain concentration at the root of the Vee. This strain is imposed on the through-thickness direction of the base metal plate and results in lamellar tearing under the root of the Vee when the material is susceptible. The amount of tearing 18 determined by breaking of $f$ the stem plate and measuring the percentage of heat-tinted fracture area. correlation of test results with fabrication history has been poor. 28 


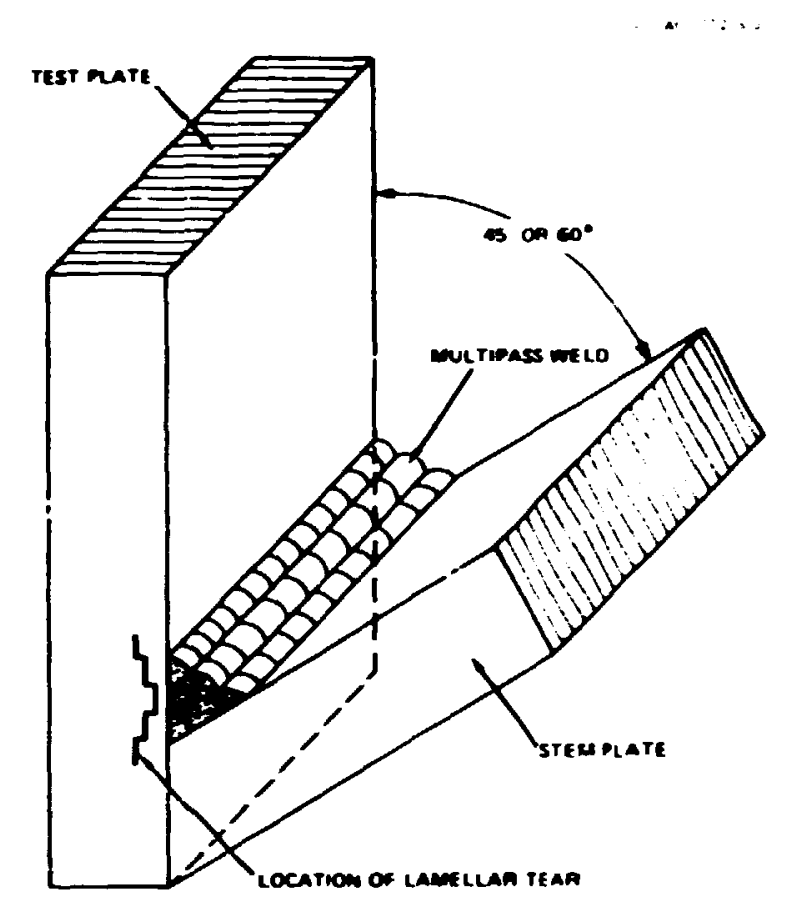

Fig. 12. Details of Cranfield Test Specimen.

Because the test conditions are so severe, ${ }^{3}$ it can only identify highly resistant materials. In addition, variability of testing conditions can make it difficult to apply uniform strain cycles in different tests. One investigation reported that, because cracking propagated only in the $\mathrm{HAZ}$, poor correlation was obtained when inclusions were outside the HAZ. The use of the Cranfield Test for production quality control would be difficult because of the variability of testing conditions and the severity of the test. No recent investigations have reported success with this test for assessing susceptibility.

In the Welding Institute Window Test, ${ }^{26}$ a plate of the base material to be tested is inserted through a rectangular hole or window in a restraining plate to form a cruciform joint. Figure 13 shows the detalls of the test procedure, adapted from ref. 26. The window sides adjacent to the two test plate surfaces parallel to the rolling plane have a Vee bevel. Single-pass, full-penetration fillet welds are initially made in two grooves on one side of the test plate to anchor ft. Similar test welds are then made in the two grooves on 

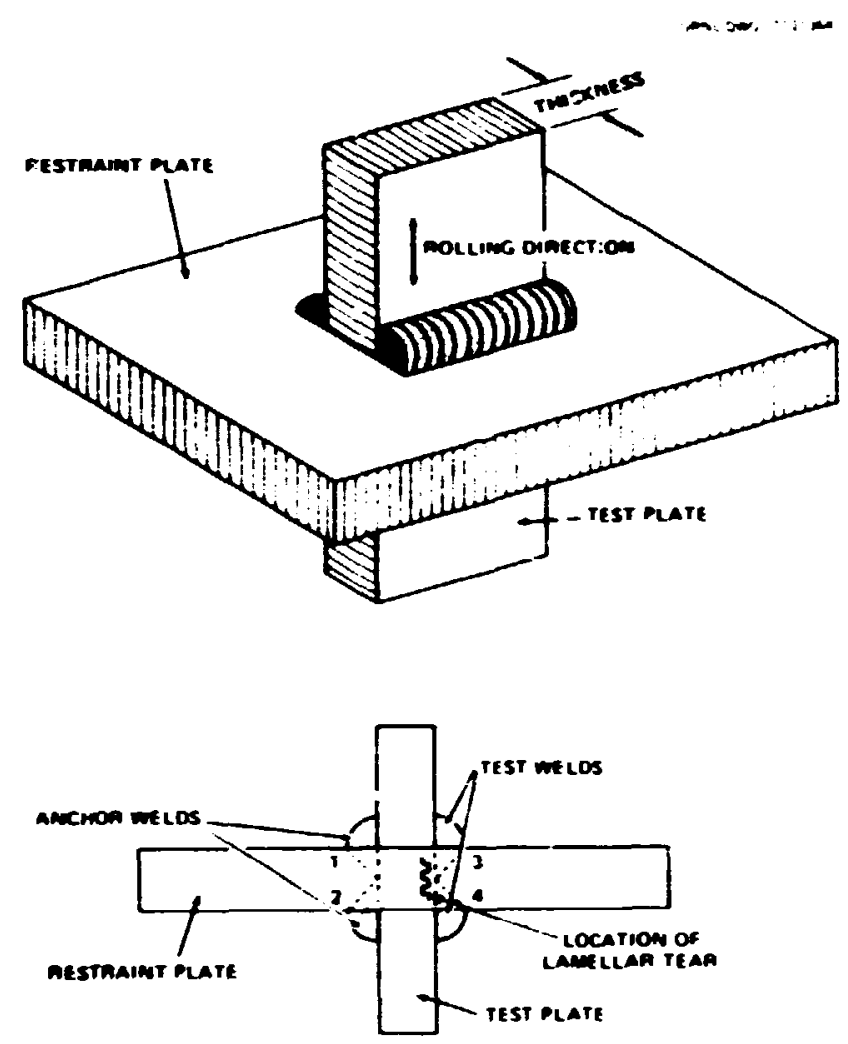

Fig. 13. Details of the Welding Institute Window Test.

the opposite side. The restraint provided b; the initial anchor welds promotes the occurrence of lamellar tearing in the test plate during the welding of the second side. Visual or setallographic observation cf tearing is the criterion for fallure. One Investigation' has reported the following difficulties with the test:

1. root cracking can induce lamellar tearing and therefore confuse the test results;

2. since the amount of restraint varies as a function of the restraining plate and test plate thicknesses, it is difficult to assess test results quantitatively.

Although this same study' has dewonstrated methods to lessen these problems, they are too complex and require carefully reproduced welding procedures. As a result of these problems, the test is not readily applicable to production quality control.

The Lehigh Lamellar Tear Test ${ }^{\prime \prime}$ was developed to enable quantitative evaluation of the variables affecting lamellar tearing. The test is 
described by its developers as suitable for laboratory use. "I Figure 14 shous the details of the test, adapted fron ref. 2. A cantilever bean is welded to the surface of a rigid vertical test plate. Throughout the test, an external load is applied to the cantilever to produce a constant through-thickness restraint on the test plate. Because a multipass weld is used, the load necessary to maintain constant restraint changes after the deposition of each layer. This variable load must be calculated from load lever arm length, width of test plate, thickness of cantilever beam, and the thickness of weld after the deposition of each layer. The criterion for assessing the susceptibility to lamellar tearing is the determination of the critical weld restraint level (CWRL) just necessazy zo cause tearing. The CWRL is determined by testing at various increasing restraint levels until cearing is detected visually, metallographically, or ultrasonically. The test has been used to examine ${ }^{2}$ a wide range of steel types and the material variables affecting tearing. Modification of the tearing susceptibility assessment criteria was necessary for evaluating welding variables. ${ }^{13}$ The test had to be instrumented to enable recording load vs joint displacement. The modified susceptibility criterion was a

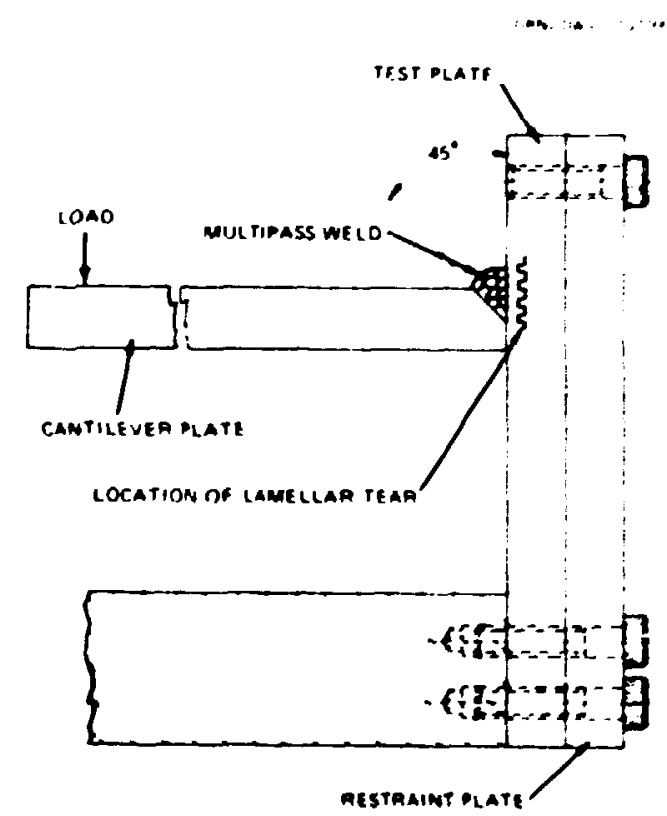

Fig. 14. Details of the Lehigh Lamellar Tear Test. 
postweld energy index $\left(E_{F}\right)$, which was calculated from the product of fracture stress and displacenent required to sause fallure. Although the Lehtgh Lanellar Tear Test has denonstrated ${ }^{2}, 11,13$ its usefulness as a laboratory tool to study pertinent variables, it does not appear to be readily applicable tor production quality control. This is due to both the complexity of the testing procedure and the absence of established acceptance criteria correlated with fabrication history.

Tests of a Prototypic Nelded Joint

The results from testing aterial in a prototypic welded joint are often very difficult to correlate with actual production situations. This is mainly due to the difficulty of duplicating the exact welding conditions and restraint that will be present during production. In addition, as with all destructive tests, the aterial that is tested may not accurately represent the piece from which it was rewoved. Because of the potential variability of welding conditions and restraint, the test inherently lacks the ability to quantitatively assess tearing susceptibllity. Jubb ${ }^{3}$ has concluded that although prototypic weldwents might be useful for investigating certain parameters, they cannot be recomended for generul gasessient of tearing susceptibility. This testing method is also undesirable for production quality control because of its complexity and expense. Although several recent investigations 5,15 have used prototypic weldments to stuid tearing variables or other test methods, none have proposed its use as a material assessment test.

DETECTION AND REPAIR OF LAMELLAR TEARS AFTER WELDING

Because lamellar tears can remain completely subsurface, such NDE Techniques as visual, dye penetrant, and magnetic particle inspection cannot be used. Radiographic examination cannot be used both because the inclusions can mask defects and because the orientation' of the tearing makes detection difficult. Ultrasonic testing is the normal metr.nd used to inspect for lamellar tears. However, the 
Interpretation of UT results can be a problea. ${ }^{1,21}$ Cases of aisinterpreted UT Indications leading to unnecessary repairs have been reported.' Sonetines an angled shear-wave UT examination is needed to detect the presence of the shedr walls, which are sharacteristic of lanellar tearing- 21 Improper equipent gain settings and acceptance criteric can also cause clusters of inclusions or afcrostructural bands to be misinterpreted as tears.' Unfortunately, the materials that are more suscsptible to lamellar tearing contain the type of defects that ake UT difficult. For exaple, thick dirty plates can attenuate ultrasound to the extent that interpretation may be difficult. Recent work at the Welding Institute 22 provides an example of this situation. Ultrasonic testing oi sections frow a box-header that falled during fabrication indicated cearing present in several locations. However, metallographic examination revealed that inclusions had decohered from the matrix, but had not linked to form cears. During censile testing of these sections, fallure occurred on other planes. The above discussion indicates uncertainty in the interpretation of results of UT of production weldments. In additfon, rellance on detection by UT to avoid lamellar tearing may be a poor substitute for selection of improved material.

litrasonic examination of finished welds or buttered layers does provide a conservative approach. The techniques arc sufficiently sensitive such that refectable tears should not be missed, but instead it is more likely that acceptable Indications may be rejected, requiring subsequent repair. When the fabricator decides to use ultrasonic examination instead of selecting material with improved ST ductility, he will be risking repair costs but yet not jeopardizing reliability.

The repair of lamellar tears can be very difficult and costly. One study" indicate: that in the repair of highly restrained connections, the repair can be more detrimental than the original weid. This is because at the time of the repair there is usually a larger amount of restraint. The additional mechanical and thermal cycles from repair welding can also simply cause tearing to occur at a greater 
depth in the plate thickness. A good exaple of this situation was provided by metallographic exanination ${ }^{29}$ of a T-butt joint used to attach a circunferential stiffener plate to a cylinder. This joint had experienced extensive tearing during fabrication and was subsequently scrapped. The exanination revealed that an atterpted repair had caused further tearing below the repair veld.

A successful repair often requires drastic procedures. These procedures aight require complete disassembly of the welded joint, grinding or gouging out the joint area and applying buttered layers, and rewelding the joint over the buttering. This type of procedure w11 of course be very expensive and cause considerable delay. Fron an econonic and schedular viewpoint, it ay be more feasible in some situations to scrap a conponent rather than try to repair it. Because of the potential problems with the repair of lanellar cears, it would appear to be economically justifiable to pay extra for inproved material properties rather than risk tearing.

\section{SIGNIFICANCE OF SERVICE LOADING OF MATERIAL SUSCEPTIBLE TO LANELLAR TEARING}

In order to evaluate the significance of lamellar tearing, the effects of service conditions on both existent tears and tear-free aterial must be considered. Generally, three types of service loadings should be considered: static, dynamic, and fatigue. Although most Investigators report only a few known cases of lamellar tearing being initiated or propagated during service loading, critical applications such as nuclear power plants and of fhore structures require increased reliability because of stringent service conditions ano the consequences of fallure.

The effect of static loading on tear-free material, within design 1inits, must be considered negligible when compared with the highly localized loading produced by the welding cycle. It has been reported' that the locallzed strains under a weld can be as high as 27 without even considering stress concentration. Because through-thickness design stresses are limited such that they are significantly below 
the yield strength of the material, * strains experienced during service will be significantly less than $0.2 Z(0.2 z$ of fet strain is norally the basis fcr defining the yield point of wost structural mate:tals). Therefore the strain that results from welding can be at least 10 times that caused by service loading. A current groupspcasored project ${ }^{29}$ at the Welding Institute is investigating the significance of lamellar tearing under static loading. Although this project is still in tes early stages with only prelininary results available, a few general trends have been detected. A portion of the work completed involved tensile testing of cruciform test picces sectioned from a component that had been scrapped because of extensive teariry during fabrication. The amount of lawellar tearing present under tiu: fillet welds of the test pieces varied from none to extensive tearing urder bsth. The results of the tensile testing showed that in most specimens the yisld strength of the base waterial was exceeded before failure despite the presence of extensfve tearfing. In the test piece with no tearing and in one with tearing under only one weld, fallure occurred by necking of the base metal rather than by excension of existing tears, as occurred in the remainder of tests. As would be expected, the failure stress tended to decrease as the amount of existing tearing increased. Although these preliminary results are very linited, they do address the two situations that must be consicired: tie effects of static loading on existing tears and tear-free material. From these results and the previous discussion of design limits, the welding appears more likely to cause tearing than static service loads. In addition, loads above the yield strength of the base metal are apparently required to propagate tears to failure even thouglı extensive tearing is present initially. However, because the faiiure stress decreases as the amount of initial tearing increases, failures could occur within design limits if the extent of initial cearing is sufficiently great.

*ASME Code Section III Division 1, Subsection NF limits the design stress intensity $\left(J_{m_{i}}\right)$ to a maximum of $1 / 3$ of che yield strength for class 1 components and $j / 3$ for classes 2 and 3 , and for throughthickness loading tha tesign stress is 1 imited to $0.5 \% \mathrm{~m}$. 
The significance of fatigue loading with respect to lawellar tearing has recelved attention recently because of critical appifcatlons such as offihore structures. In one study, ${ }^{30}$ a heat of ABS (Anerican Bureau of ShIpping) Grade EH 32 normalized steel with above average otatic ST properties (ST $Z$ RA was greater than 20z) intended for use in an offshore semisubmersible drill rig was tested in fully reversed, axial load-controlled fatigue. Although attachment welds were used to fabricate the ST fatigue test specinens, no lamellar tearing was detected by UT, visual Inspection, or metallographic examination of selected specimens. This testing is therefore applicable to the effects of fatigue loading on material that is initially cear-free. The results of the testing showed that the ST direction had several times shorter fatigue 1 ife and 20 to $30 \%$ lower fatigue strength than the longitudinal direction. These differences were greatest for high-cycle fatigue (greater than $10^{5}$ cycles), where the sensitivity to inclusion content, distribution, size, and shape incriases. In the ST direction the fatigue mechanism displayed several ruptur $=$ s.odes, consisting of quasi-lamellar tearing (decohesion at inclusion interfaces, tearing, and cleavage) and fatigue striation. However, ductile striation-type rupture dominated the longitudinal direction. Inclusions both initiated and propagated fatigue cracks in the ST direction, while in the longitudinal direction they were insignificant.

Th: Welding Institute ${ }^{31}$ studied fatigue crack propagation in tear-free material and weldments containing lamellar tears. Four steels with varying susceptibility to lamellar tearing were tested. The tear-free material was investigated with axially loaded, centernotched plate specimens and edge-notched bend specimens, while sections of a cruciform joint were used to study the weldments. In testing of the tear-free material, the steel with the lowest ST \% RA had the greatest fatigue crack propagation rate. As previously reported, 30 the rupture mode consisted of both fatigue striation and quasi-lamellar tearing. Increases in the amount of quasi-lamellar tearing mode caused the crack propagation rate to increase. However, the results 
also indicate that a material wust have exiremely poor ST properties before the fatigue crack propagation rate is serfously affected. The evaluation of fatigue loading on existing lamellar tears was limited to one steel because tearing did not occur in the cruciform joints of the other three. The amount of tearing present in the joints from the one steel varied from zero to $20 \%$ of the load-carrying area. The results of the testing indicated that the fatigue strength did not change as the amount of initial tearing increased. However, this was attributed to the exceptionally low ST properties of the steel. During the testing of the steels that did not contain tears, all the fallures initiated at the weld toe. However, on the basis of the initial crack propagation studies, it was predicted that if tears were initially present in these steels they could propagate to failure. For high-cycle fatigue (greater than $10^{6}$ cycles) it was concluded that failure would always occur at the weld toe of the crucisorm joint for any of the steel:s. This is because of the high stress cencentration at the weld toe.

Another study ${ }^{32}$ investigated the effects of three different steelmaking practices on fatigue crack propagation. Heats of ASTM A 533B steel made by conventional steelmaking practice (CON), calcium treatment (CaT), and electroslag remelting (ESR) were tested by use of compact wedge-opening-load fatigue specimens. A ST Z RA of $20 \%$ for the CON material indicated that its ST ductility was not low. The results showed that the fatigue crack growth rate in the ST direction of the CON material was considerably higher, while the CaT and ESR materials had significantly improved isotropy with overall improvement and reduction in scatter. The improvement in fatigue crack growth rate was attributed to alteration of inclusion morphology and distribution. Observations of the fracture surfaces of the CON material agreed with the previously reported studies, 30,31 which showed inclusions affecting the ST direction but not the longitudinal direction. In addition, the same quasi-lamellar tearing decohesion of inclusions was shown to be responsible for the increased growth rates in the ST direction. 
The following conclusions can be drawn from the results of the three previously described sticies. The fatigue properties of tear-free steels ade by CON can show anisotropy in the ST direction even though the ST ductility is above levels where lanellar tearing occurs. However, stress concentrations at the root or toe of welds would likely be wre detrimental in tear-free material unless the ST ductility is very low. In steels with initialiy existing lanellar tearing, the tears appear to be most detrimental to fatigue loading. For high-cycle fatigue (greater than $10^{6}$ cycles), stress concentrations at the root or toe of the weld may be wore detrimental than existiug tears or poor ST ductility.

In ASIE Code ${ }^{17}$ Subsection III-NF, linear supports of classes $1,2,3$, and MC have fatigue stress range limits (as specified in Section III Appendices Article XVII-3000) for loading cycles greater than $20 \times 10^{3}$ cycles. The limits are based on the stress cacegory (type of member and loading) and the number of cycles. The allowable stress ranges for full and partial penetration $T$-joints transmiteing a load in the through-thickness direction are penalized by approximately 40 and $60 z$, respectively. Since these limits account for weld stress concentrations that can be potentially more detrimental, the design margin against lamellar tearing during fatigue loading appears adequate. However, there are no fatigue design limits for plateand-shell type supports or for loading cycles less than $20 \times 10^{3}$. In discussions with members of the ASME Code Working Group on Component Supports (SG-D) (SC III), we were not able to ascertain whether fatigue ifmits were omitted in these situations because of their insignificance.

Recent investigation of the effects of dynamic loading with respect to lamellar tearing has mainly been limited to CVN testing of steels to assess tearing susceptibility. However, some investigations ${ }^{3}$ of the effects of shock loading welded structures have been performed. In a study ${ }^{33}$ at the Naval Construction Research Establishment in Scotland, explosion tests of full-penetration T-joints were performed on three stee1s: H.Y. 80, O.T. 35 (a U.K. grade of quenched-andtempered C-Mn-Ni-Cr Steel), and B quality (a U.K. grade of fully 
killed and normalized C-Mn steei). Both the Q.T. 35 and B quality steels had histories of lamellar tearing during fabrication, while the H.Y. 80 is not normally considered susceptible. The results of the explosion tests showed that the Q.T. 35 and B quality steel T-joints failed completely by lamellar tearing, while the H.Y. 80 T-joints suffered only limited ductile tearing at the weld toe. These results demonstrate that dynamic loading can cause the formation and propagation to failure of Ifedlar tears. These tests again show that if the steel has sufficient ST ductility, the stress concentration at the weld toe can be the limiting factor in dynamic loading, as was the situation for fatigue.

Reduced ST CVN properties have been reported $5,10,11$ for tear-free $A$ 515, A 516, and A 533B steels made by CON. In addition, reduced ST dynamic tear (DT) properties have been reported ${ }^{10}$ for tear-free A. 533B steel made by CON. These results along with che limited explosion testing of weldments indicate that the ST directions of these steels are more susceptible to failure by lamellar cearing and brittle fracture mechanisms during dynamic loading. Although no specific investigations of steels with existing tears are known to this author, the presence of existing cracks can only decrease the resistance of the material to fallure during dynamic lcading. Since selection of material with improved properties is the only design procedure for ensuring resistance to fallure during dynamic loading, mandatory ST ductility requirements should be specified for Subsection III-NF components that may be dynamically loaded.

\section{RECOMMENDATIONS FOR AVOIDING LAMELLAR TEARING DURING} FABRICATION OR SERVICE IOADING

The most effective means for avoiding lamellar cearing is through the use of material with improved ST ductility. However, selecting better material increases costs. With the advent of inspection requirements and more sensitive UT techniques, the detection of lamellar tears that result from fabrication has increased. Because these tears must be eliminated by costly and sometimes ineffective repairs or by 
disasembly and replacenent of the defective aterial, the increased coste for Improved material are now wore justiflable. Inproved aterials are already being used in critical service applications. Requiremente for steels to be used in critical components of of fshore structures have already specified lower sulfur contents, ainimu ST tersile atrength, alnimin ST $X$ RA, and maximen allowable Inclugion content. ${ }^{21,30}$ Table 3 show some selected material requirements ${ }^{36}$ for critical componts in North Sea of fshore structures.

Table 3. Selected Material Requirements for Critical Components in North Sea of fshore Structures

\begin{tabular}{llll}
\hline $\begin{array}{l}\text { Offshore } \\
\text { Platfora }\end{array}$ & \multicolumn{1}{c}{ Application } & $\begin{array}{c}\text { Maximum } \\
\text { Sulfur } \\
(\boldsymbol{Z})\end{array}$ & \multicolumn{1}{c}{ ST Z RA } \\
\hline B.P. Forties & Node tubes & 0.010 & $\begin{array}{l}20 \text { (mean of 6) } \\
15 \text { (min individual) }\end{array}$ \\
Shell Brent & Nodes & 0.015 & $>35$ (mean of 6) \\
& Node type bracing & 0.015 & $\geqslant 35$ (meait of 6) \\
\hline
\end{tabular}

Figure 15 shows two design paths for avolding lamellar tearing during fabrication or service loading. One path is required for class 1 and the other may be followed for classes 2, 3, and MC component supports. The information contained in this figure provides a synopsis of the corclusions from the foregoing assessment of lamellar tearing. The difference between the two paths is that the one for class 1 component supports requires the use of material with Improved ST ductility, while the path for the other classes does not. Although material improvement is preferable, less critical applications, cost, and avallability of materlal may make the alternate path more desirable and therefore justify it being an option. However, the reliability of the path for classes 2, 3, and MC component supports is assured by two mechanisms. First, the service loading must always be considered. For dynamic loading, Improvement of the material's ST properties 18 mandatory. Second, ultrasonic examination of the finished weld or buttered layer is required. 

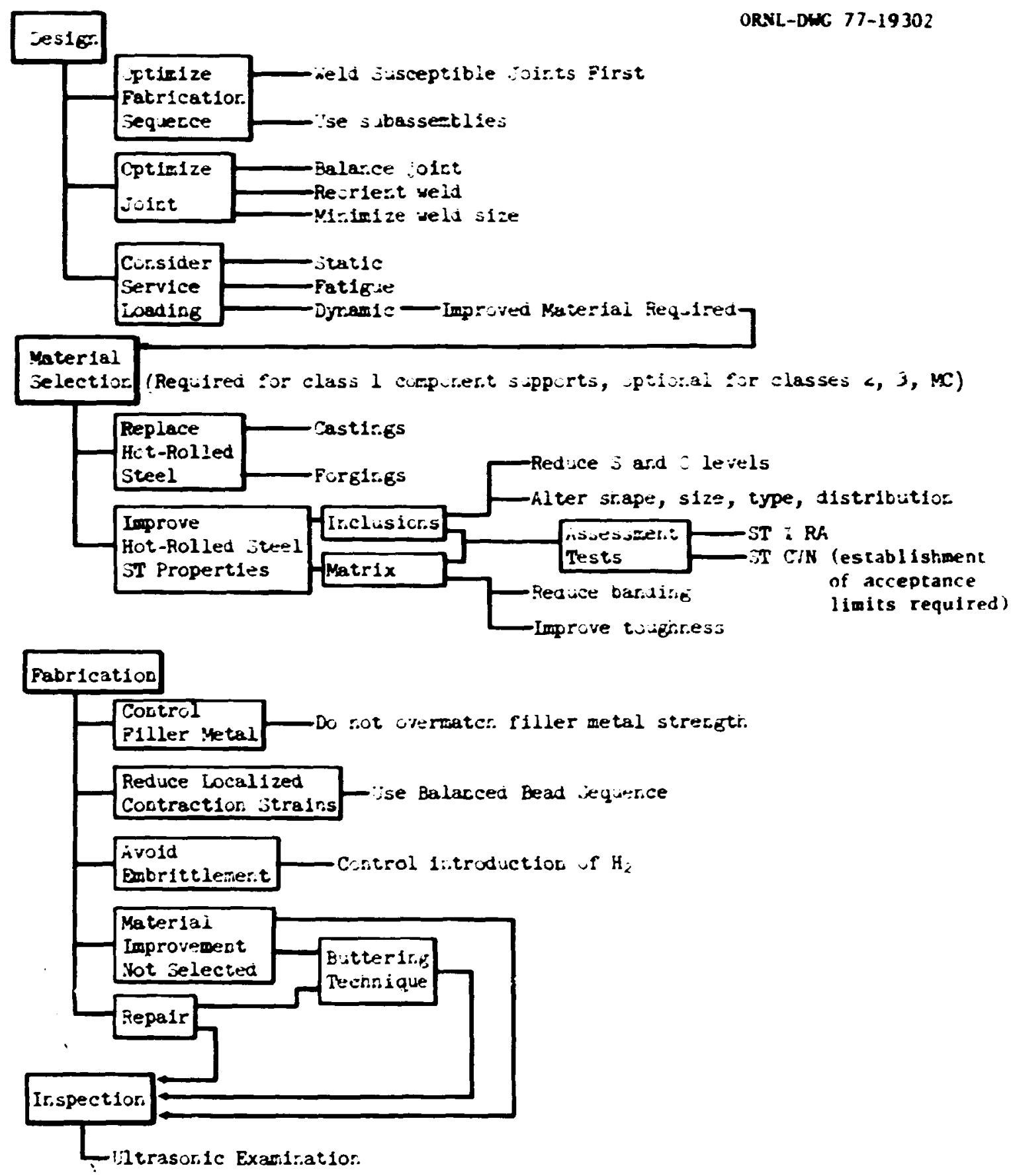

Ftg. 15. Design Paths for Avoiding Lamellar Tearing During Fabrication of Service Loading of Section III Division 1, Subsection NF Component Supports. 
The fcllowing surary highlights the conclusions oresented in 718. 15. The avoldance of lamellar tearing must begin at the design stage. The service loading should be considered, and mandatory ST meterial requirements specified for dynanic loading. The joint design should be optinized by balancing the joint, reorienting the weld if possible, and antrizing the size of the weld. The fabrication sequence should be optinized by welding susceptible joints first or by using subassemblies to mininize the restraint. Material susceptibility to tearing can be avoided by either replacing the hot-rolled steel with another product form or selecting material with improved ST properties. A decision to replace hot-rolled steel with a casting or forging must weigh the economic consequences. The improvement of the hot-rolled steel should be aimed at both the inclusions and the matrix. The addition of rare earth metals or the use of advanced steelmaking techniques such as calcium treatment or electroslag remelting can be used to reduce sulphur and oxygen levels and alter the shape, size, type, and distribution of inclusions. The matrix properties should be upgraded by reducing the banding and improving the toughness. The test that is currently most applicable to material assessment In a production environment is ST $z$ RA. When this test employs a sufficient sampling plan with conservative acceptance 1 imits, it should provide an adequate means of assuring freedom from tearing. The use of the ST CVN Test provides a method to evaluate the toughness of the matrix. However, additional work is required to establish acceptance criteria for this test.

Several considerations are important in reducing the risk of tearing during fabrication. The filler metal should be controlled so that it does not overmatch the strength of the base metal. The localization of contraction strains should be reduced by using a balanced bead deposition sequence. Embrittlement of the HAZ shculd be avolded by using techniques to eliminate the introduction of hydrogen. The buttering technique can be used to lessen the risk of tearing in materials without improved ST properties or for repair. Ultrasonic inspection should be required when material with unimproved ST properties is used or when the buttering technique is employed. 
ASSESSMENT OF ASME CODE REQUIREMENTS

Currently AStE Code Section III Division 1, Subsection NF has only one requirement to deal with lamellar tearing or poor ST ductility. This requirement limits the stress at the contact surface of a weld transmitting a through-thickness ioad to $50 \%$ of the design stress intensity $\left(S_{m}\right)$. However, the ef fect of this requirement has been to cause designers to increase the size of welds to reduce the stress. Since increased weld size worsens the risk of lamellar tearing as previously described, the Code comittee is currently planning to eliminate this stress limitation from Section III Division 1, Subsection NF. Since the design stress intensity $\left(S_{m}\right)$ would still be considerably below the yield strength, as previously discussed, this should not increase the risk of tearing. As a replacement for this limitation on stress, a limitation should be placed on the ..ize of the weld. One possible method would be to limit the cross-sectional area of a weld at the contact surface where it produces a tensile load in the through-thickness direction. The limitation on the weld crosssectional arca should be based upon the load-carrying area of the smaller of the two members being joined. An allowance must be made for additional reinforcement that the welder may afd. Typically, this additional reinforcement could be $10 \%$ on either side of the weld. Therefore, a possible requirement might be that the cross-sectional area of a weld at the contact surface where it produces a censile loar: in the through-thickness be less than $120 \%$ of the load-carrying area of the smaller of the two members being joined.

The specifications permitted by ASME Code ${ }^{17}$ Sertion III and Code Case N-71 (formerly 1644-6) for materials that are potentially susceptible to lamellar tearing are shown in Table 4. It should be remembered that susceptibility to lamellar tearing depends largely upon the steelmaking practice used to manufacture hot-rolled plates and shapes of carbon and low-alloy steel. Materials produced to some of the specifications listed in Table 4 will be more susceptible than others. However, this difference in susceptibility is not necessarily due to different requirements in the sperifications. 
Table 4. Material Specifications Permitted by ASME Code Section III-NF But Potentially Susceptible to Lamellar Taering

\begin{tabular}{|c|c|c|c|c|c|}
\hline \multirow{2}{*}{ Specification } & \multirow{2}{*}{ Description } & \multicolumn{4}{|c|}{$\begin{array}{l}\text { Appl I cable Conponent } \\
\text { Support Clasaes }\end{array}$} \\
\hline & & $\mathbf{1}^{\mathbf{a}}$ & $2^{b}$ & $3^{c}$ & $m c^{d}$ \\
\hline$S A-285^{e}$ & Carbon steel plate for pressure vessel: & 1 & 1 & 1 & 1 \\
\hline$S A-442$ & Carbon steel plate for pressure vessels & l & 1 & 1 & 1 \\
\hline$S A-51 S^{e}$ & Carbon steel plate for pressure vessels & l & 1 & 1 & 1 \\
\hline$S A-516^{e}$ & Carbon steel plate for pressure vessels & 1 & 1 & 1 & 1 \\
\hline SA-537 & Carbon steel plate for pressure vessels & l & 1 & 1 & 1 \\
\hline Sn-299 & Carbon steel place for pressure vessela & 1 & 1 & 1 & 1 \\
\hline $5 A-204$ & Low-alloy steel plate for pressure vessels & 1 & 1 & I & 1 \\
\hline$S A-302$ & Low-alloy steel plate for pressure vessels & 1 & 1 & 1 & 1 \\
\hline$S A-533$ & Low-alloy steel plate for pressure vessels & 1 & 1 & 1 & 1 \\
\hline$S A-36^{e}$ & Structural carbon steel plate and shapes & 1 & ' & ' & 1 \\
\hline A $572^{\mathrm{e}}$ & High-strength low-alloy steel plate and shapes & 1 & I & I & 1 \\
\hline A 588 & High-strength low-alloy steel plate and shapes & l & I & ' & 1 \\
\hline$S A-612$ & Carbon steel plate for pressure vessels & & 1 & 1 & 1 \\
\hline$S A-283^{e}$ & Structural carbnn steel plates & & & I & 1 \\
\hline
\end{tabular}

aFrom ASME Poiler and Pressure Vessel code Sect. III, DIV. I Appendices, Tables I-1.1 and I-11.1; ASME Code Case N-71, Table 1.

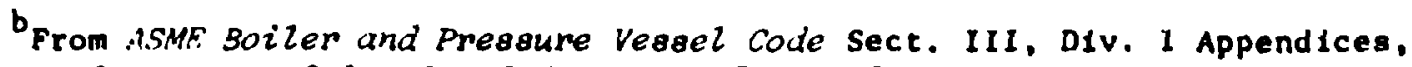
Tables 1-7.1 and I-12.1; ASME Code Case $\mathrm{N}-71$, Table 2.

'From ASME' Boiler anl Pressure Yessel Colé Sect. III. DIv. I Appendices, Table I-8.1.

dFrom ASME Boiler and Presoure Vesel Code Sect. III. DIV. I Appendices, Table I-10.0.

EHistory of lamellar tearing, reported by $S$. Ganesh and R. D. Stout, WeL.J. J. (Miami)

55(11): 341-s-354-s (November 1976), or D. A. Canonico, ORNL, private communication. 
These specifications generally allow a wide range of steelmaking processes (open-hearth, basic-oxygen, electric-iurnace, vacuu-arc remelt, or electroslag remelt), deoxidation practices (rinned, capped, senikilled, killed, killed plus aluanum for fine grain practice), sulfur content (0.04-0.05\% maxima), and silicon content (0.15-0.30z). Therefore disallowing the use of certain specifications will not be an adequate solution to the lamellar tearing problem. However, the use of an ST $z$ RA requirement will force the designer and the steel producer to select the steelmaking practices necessary to Improve ST ductility. Table 4 shows that five of the material specifications allowed for class 1 component supports have a reported history of lanellar tearing. Because of the critical nature of class 1 components, this situation highlights the need for mandatory ST ductilty requirewents in class 1 component support materials that will contain a weld transnitting a load in the through-thickness direction.

Since the redesign of weld joints, other than completely eliminating through-thickness strain in rolled plates or shapes, cannot always elininate tearing in sus:eptible material, mandatory joint designs do not seem appropriate. However, the addition of pre-erred joint designs to Code ${ }^{17}$ Subsection III-NF Fig. NF-3291(a)-1 requirements for plate and shell supports and the CODE ${ }^{17}$ Section III Appendix XVII-2450 requirements for linear supports would be appropriate. Examples of some preferred joint designs are discussed in a previous section.

The ASME Code Subgroup on Fabrication and Examination (SC III) is currently formulating requirements for welds that transmit a throughthickness load in rolled plates and shapes of Subsection III-NF component support primary members greacer chan $16 \mathrm{~mm}(5 / 8 \mathrm{in.})$ in thickness. The currently ${ }^{35}$ proposed requirements provide options to either ultrasonically examine finished welds, weld on an ultrasonically examined Inlay or overlay, or test the base metal to meet an ST $\%$ RA of 207 for a single test. In addition, the minimum specified tensile strength of the filler metal is not allowed to exceed that. of the base metal by more than $83 \mathrm{MPa}(12 \mathrm{ksi})$. These requitrements are afmed at the Subsection III-Nip fabrication and installation article 
and do not interface vith the enterials and deafon articles as recomeaded in P18. 15. The proposed requirenents should Incorporate design consideration of component support class and service loading. Hadatory enterials requirements should be included for class 1 composent supports or service conditions that ay experience dynanic loeding.

The decision to linit requirenents to aterial grester than 16 m ( $5 / 8$ in.) In thickness is not totally supported by a reported' survey of fabricators. In this survey lawellar tearing was reported by 202 of the fabricators in situations in wich the plate thickness did not exceed $13=(1 / 2$ in.). Although 952 of the fabricators reported tearing to occur in thicknesses between 13 and 64 wa $(1 / 2$ and $21 / 2$ in.), the potential for tearing in highly restrained thin plates cannot be overlooked. In addition, a recent study ${ }^{36}$ has shown that the inclusions In thin plate can be wre elongated than those in heavy plate if the rolling ratio (ratio of prinary rolling to cross rolling) is not kept 10w. As a result of the above considerations, it may be prudent to require Ipproved ST ductility in all thicknesses of class 1 component supports, and require the use of one of the three options in thicknesses above 16 (5/8 in.) for all other classes.

As previously discussed, the optional use of ultrasonic exanination of finished welds or welding on an ultrasonically exanined buttered layer for materials that do not have improved ST ductility is an acceptable procedure if component support class and service loading are considered. The methods described for ultrasonic exanination and buttering in the proposed requirements appear to follow the procedures recomended in the literature. In addition, the limitation on filler netal strength is a good requirement.

The proposed requirements for spectfying a minimum ST $z$ RA need to be revised. As previously recomended, the ST \& RA requirements should be linted to steels with yield strengths less than $400 \mathrm{MPa}$ (58 ks1). The requirement for a single tensile test with a minimum ST $\pi$ RA of $20 \%$ needs to be nodified to provide a more conservative acceptance 1int. The need for a higher ST $Z$ RA can be fustified 
because of the large variations that comonly occur between 0 and 202. Dolby has recently reported ${ }^{37}$ that although Helding Institute experience has shown that an ST $Z$ RA of $20 Z$ (for a set of six specinens) is adequate to avold tearing in highly restrained joints, a wore conservative ainima ST $Z$ RA such as 257 is necessary to make allowance for such factors as inclusion segregation. In addition, a recent Helding Rescarch Council Bulletin," which presents an international bibllography on through-thickness properties and lanellar tearing, points out the need for statistical control over ST Z RA requirements because of their variability. As an example, recent changes in specifications for materials for of fshore construction are cited. Whereas two to three years ago an $S T Z$ RA of 207 was used, recent specifications require a minimu individual value of 107 with a 357 einitum average for a set of six specimens. ${ }^{30}$ A Dinimu ST I RA of $25 \pi$ is the acceptance limit used for the nost rellable steel grades in French and German standards. 21 The cesting of a set of six specimens should also be required to improve the statistical representativeness of the test. Existing specifications are currently requiring sets of 3 to 6 specimens. The size of specimens and the extraction procedure should be standardized. Since it is advantigeous to use a large specimen diameter and possibly include the plate surface regions in the specinen gage length, these factors should be considered when establishing standard specimen size and extraction procedures. In addition, requirements should be established for the welding of grip attachments to plate surfaces. The range of product thicknesses from a given heat that a set of tests can represent wust also be specified. As previously reported, ${ }^{36}$ the amount of reduction can affect the degree of inclusion elongation and thereby influence ST iuctility.

\section{CONCLUSIONS}

A need is evident to establish requirements to redise tine risis of lamellar tearing in critical applications such as Niclear Puwer 
Plants. However, because of the controversy ourrounding the variou aspects of lancllar tearing, It has been difficult to establish univerally accepted requirenents. The design paths shown in F18. 15 along with the specific recomended acceptance linits and teating conditions provide usable requireants that are based upon both fabrication experience and research progran. While it may appear to some that these requirements are too conservative, this apparent conservatisa is needed to bridge the gaps in the controversal r.spects of lamellar tearing-

The results of this assessment indicate that the improvenent of waterial properties is undoubtedly the best approach for reducing the risk of lamellar tearing. However, it was also recognized that under certain service loading conditions in noncritical applications, the use of ultrasonic exanination or buttering can provide acceptable wethods for reducing the Ist of tearing. This sizuation highlights the fact that the requirements that are recomended as a result of this assessment were aimed at both reducing the risk of lamellar cearing and providing flexibllity to fabricators when possible.

\section{ACXAOWLEDGIENT}

I would like to acknowledge D. A. Canonico and H. A. SImpson, Jr. for reviewing this paper, S. Peterson for editing, and Gatl Gollther for typing the manuscript.

\section{REFERENCES}

1. J.C.M. Farrar and R. E. Dolby, "Lamellar Tearing in Welded Steel Fabrication," In Phase I of Investigations into Lameliar Tearing. A Compendium of Reports from a Sponsored Research Prozrame, The Welding Institute; Cambridge, England, March 1975.

2. S. Ganesh and R. D. Stout, "Material Variables Affecting Lamellar Tearing Susceptibility in Steels," Weld. J. (Miami) 55(11): 341-8-354-8 (November 1976). 


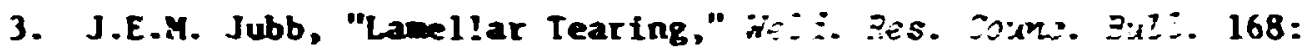
1-14 (Deceaber 1971).

4. "Comentary on Highly Restrained Welded Cunnections." iIS Er:: 1973: 61-73.

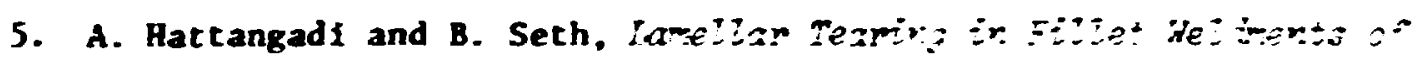
Pressure lesse: Exbrizontions, American Society for Metals Technical Report Systea : $10.76-30$ (1976).

6. J.C.M. Fartar, K. E. Dolby, and R. G. Baker, "Lamellar Tearing in

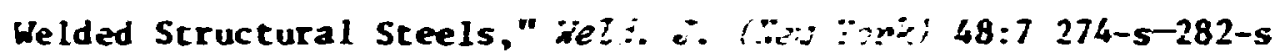
(July 1969).

7. B. Kato and K. Sorita, "On the Static Anisotropy of the Structural Steel Place," pp. $66-69$ in the Joinisethth Japry Corgress on:

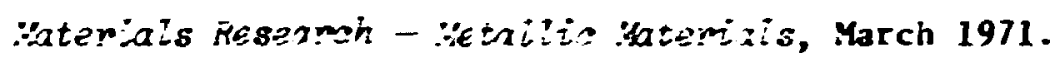

8. J.C.M. Farrar and R. E. Dolby, "Lamellar Tearing in Helded Steel Fabrication - The Role of Sulfide Inclusions," pp. 252-68 in Sul:ite Inciusions in Stee:, Anerican Society for Metals, Metals Park, Ohio, 1975.

9. S. Kanayawa et al., "On the Assessment of the Lamellar Tearing Susceptibility of Steel Plate," 3rors. J:n. del:. Sos. 5(1): 2-14 (April 1974).

10. A. D. Wilson, "The Ef fect of Advanced Steelmaking Techniques on t!c Inclusions and Mechanical Properties of Plate Steels," presented at Symposin on Toughess charatemizxtion an: Sreaificition:s :on ISLL: and Structumi Steels, AIME Annual Meeting March 6-10, 1977.

11. R. P. Oates and R. D. Stout, "A Quantitative Heldability Test for

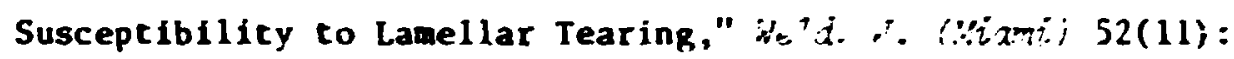
481-5-491-s (November 1973).

12. J.C.M. Farrar, "Inclusions and Susceptibility to Lamellar Tearing

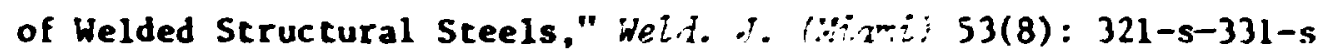
(August 1974).

13. S. Ganesh and R. D. Stout, "Effect of Welding Variables on Lamellar

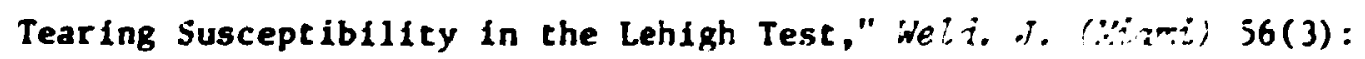
78-s-87-s (March 1977). 
14. Private comanlcation with $T$. G. Davey, The Welding Institute, April 7, 1977.

15. J.C.M. Farrar, E. N. Gregory, and R. E. Dolby, "The Problem of Lamellar Tearing. The Fabrication of Welded Testpieces: Mechanical Test Criteria for Avolding Lamellar Tearing and the Effects of Some Welding Procedural Variables on Lamellar Tearing," in Phase VI of Investigations into Lamellar Tearing. A Compendium of Reports from a Sponsored Research Procrame, The Welding Institute, Cambridge, England, March 1975.

16. Helding Handbook. Scrtion One, Sixth Edition, AWS 5.40-5.43 (1968).

17. ASME Boiler and Pressure Vessel Code, 1977 ed. with Addenda through Sumer 1977, American Society of Mechanical Engineers, New York, 1977.

18. J.C.M. Farrir et al., "The Assessment of Susceptibility to Lamellar Tearing by U1trasonic Means," and a serles of six progress reports "The Problem of Lamellar Tearing. The Assessment of Susceptibility to Lamellar Tearing by Ultrasonic Means," in Phase $\mathbf{V}$ of Investigations into Lamellar Tearing. A Compendium of Reports from a Sponsored Research Prograrme, The Welding Institute, Cambridge, England, March 1975.

19. J.C.M. Farrar, "The Uitrasonic Assessment of Susceptibilfty to Lamellar Tearing - The State of the Art," Weld. Inst. Res. Bull. 17(8): 205-08 (August 1976).

20. C. Tamburell1, "Use of Ultrasound in Assessing the Susceptibility of Steel to Lamellar Tearing," Non-Destr. Test. (Guildford, En, Z.) 10(1): 3-8 (February 1977), as cited by Current Awareness BulL. 8(13): 3 (July 8, 1977), Metals and Ceramics Information Center, Battelle, Columbus, Ohio.

21. Private communication with T. G. Davey, The Welding Institute, Aug. 11, 1977.

22. Notes from the Meeting of Sponsor Group 5513, The Significance of Lamellar Tearing, The Welding Institute, June 1, 1977. 
23. J.C.M. Farrar, "The Problem of Lamellar Tearing. The Relationship Between Short Transferse $Z$ RA Values and the Incidence of Lamellar Tearing," in Phase IV of Investigrtions into Lamellar Fearing. A Compendium of Reports from a Sponsored Research Programe, The Welding Institute, Cambridge, England, March 1975.

24. B. J. Ginn and J.C.M. Farrar, "The Problem of Lamellar Tearing. The Development of a Sifce Bend Test to Assess Susceptibility to Lanellar Tearing," In Phase IV of Irivestigations into Lamellar Tearing. is Compendium of Reports from a Sponsored Reserach Programe, The Welding Insittute, Cambridge, England, March 1975.

25. M. L. Drury and J.E.M. Jubb, "Lanellar Tearing and the Slice Bend Test," Weld. J. (Miami) 52(2): 88-s-95-s (February 1973).

26. J.C.M. Farrar and R. E. Dolby, "An Investigation into Lamellar Tearing," Met. Constr. Br. Weld. :. I: 32 (1969).

27. J.C.M. Farrar, "The Problem of Lamellar Tearing. The Assessment of Susceptibility to Lamellar Tearing Using a Short Transverse Notched Bend Test," in Phase IV of Investigations into Lamelzar Tearing. A Compendium of Reports from a Sponsored Research Programe, The Welding Institute, Cambridge, England, March 1975.

28. D. N. Elliote, "Lamellar Tearing in Multi-Pass Fillet Joints," Weld. J. (New York) 48(9): 409-s-416-s (September 1969).

29. T. G. Davey et al., The Significance of Lamellar Teaming, Progress Report for Group-Sponsored Project 5513, The Welding Institute, May 1977.

30. C. J. Adams and E. P. Popov, "Through Thickness Fatigue Properties of Steel Plate," Weld. Res. Courc. Bult. 217: 1-13 (July 1976).

31. S. J. Maddox, "The Problem of Lamellar Tearing. The Significance of Lamellar Tears with Respect to Fatigue Loading," Phase VII of Investigations into Lamellar Tearing. A Compendium of Fieports from a Sponsored Research Programe, The Welding Institute, Cambridge, England, (March 1975).

32. A. D. Wilson, "Fatígue Crack Propagation in A533B Steels," Paper 76-WALPV-6 (1976), presented at the Winter Annual Meeting, New York, Dec. S-10, 1976, of the American Society of Mechanical Engineers. 
33. A.D.E. Thomson, P. R. Christopher, and J. Bird, "Short Transverse Properties of Certaln High-Stringth Steels," J. Eng. Ind. 90: 627-35 (1968).

34. J. A. Chapaen, A. Clark, and P. R. Rirkwood, "Steels for North Sea Structures," presented at Welding in Offshore Structures, Newcastle, UX, 1974.

35. Proposed paragraph NF-4430 accepted at the Nov. 1, 1977, meeting of the ASFI Code Subgroup on Fabrication and Examination (SC III).

36. A. D. Wilson, "The Influence of Mhickness and Rolling Ratio on the Inclusion Behavior in Plate Steels," presented at the ASM 1977 Materials Confereace, Chicago, I11., Oct. 25-27, 1977.

37. R. E. Dolby, "The Keldability of Low Carbon Structural Steels," Weid. Inst. Res. Bull. 18(8): 209-16 (August 1977).

38. D. H. Skinner and M. Toyama, "Through Thickness Properties and Lamellar Tearing (a Bibliography)," Weld. Res. Counc. Bull. 232: (November 1977). 